\title{
Uranyl Ion Complexes with Chiral Malic and Citramalic, and Prochiral Citric and Tricarballylic Acids: Influence of Coligands and Additional Metal Cations
}

\author{
Pierre Thuéry*[a] and Jack Harrowfield*[b] \\ [a] NIMBE, CEA, CNRS, Université Paris-Saclay, CEA Saclay, 91191 Gif-sur-Yvette, France \\ E-mail: pierre.thuery@cea.fr \\ http://iramis.cea.fr/nimbe/ \\ ${ }^{[b]}$ ISIS, Université de Strasbourg, 8 allée Gaspard Monge, 67083 Strasbourg, France \\ E-mail: harrowfield@unistra.fr \\ https://isis.unistra.fr/
}

\begin{abstract}
Keywords: Uranium(VI) / Carboxylic acids / Structure elucidation / Hirshfeld surface / Coordination networks
\end{abstract}

Abstract. Seven homo- or heterometallic uranyl ion complexes with $R, S$-malic $\left(\mathrm{H}_{3} \mathrm{ml}\right), R$-citramalic $\left(\mathrm{H}_{3} \mathrm{cml}\right)$, citric $\left(\mathrm{H}_{4} \mathrm{Cit}\right)$ and tricarballylic $\left(\mathrm{H}_{3} \mathrm{tca}\right)$ acids were obtained under (solvo-)hydrothermal conditions and characterized by their crystal structure and, for five of them, their uranyl emission spectrum. All the malate, citramalate and citrate complexes contain the frequently observed 2:2 dimeric uranyl subunit in which the alkoxide group is bridging, these subunits being generally assembled into one-dimensional (1D) polymeric chains by bridging carboxylate groups. $\left[\left(\mathrm{UO}_{2}\right)_{4}\left(\mathrm{ml}_{2}\left(\mathrm{C}_{2} \mathrm{O}_{4}\right)(\mathrm{NMP})_{4}\right] \quad(\mathbf{1})\right.$ and $\left[\left(\mathrm{UO}_{2}\right)_{2} \mathrm{Cu}_{2}\left(\mathrm{ml}_{2}\right)_{2}\left(\mathrm{C}_{2} \mathrm{O}_{4}\right)(\text { phen })_{2}\right](2)$, which contain oxalate anions formed in situ, crystallize as twodimensional (2D) networks, the increase in dimensionality being provided by uranyl or copper oxalate bridges. $\left[\left(\mathrm{UO}_{2}\right)_{2} \mathrm{Ni}(\mathrm{cml})_{2}(\mathrm{cyclam})\right](3)$ is also a $2 \mathrm{D}$ species, while $\left[\left(\mathrm{UO}_{2}\right)_{2} \mathrm{Cd}(\mathrm{cml})_{2}(\right.$ bipy $\left.)\left(\mathrm{H}_{2} \mathrm{O}\right)_{2}\right](4)$ crystallizes as a three-dimensional (3D) framework (even if Cd" cations are disregarded). [( $\left.\mathrm{UO}_{2}\right)_{2} \mathrm{Zn}(\mathrm{Hcit})_{2}(\text { bipy })_{2}\left(\mathrm{H}_{2} \mathrm{O}\right)$ ] (5) is a $1 \mathrm{D}$ polymer with decorating $\mathrm{Zn}(\text { bipy })_{2}\left(\mathrm{H}_{2} \mathrm{O}\right)^{2+}$ groups, while $\left[\left(\mathrm{UO}_{2}\right)_{2} \mathrm{Cd}(\mathrm{Hcit})_{2}(\text { bipy })_{2}\right](6)$ is a $2 \mathrm{D}$ network. $\left[\left(\mathrm{UO}_{2}\right)_{2} \mathrm{~Pb}(\mathrm{tca})_{2}\left(\mathrm{H}_{2} \mathrm{O}\right)_{4}\right](7)$, in which the three carboxylate groups are chelating and two of them further bridging, is a 3D framework. The uranyl emission spectra of complexes 3-6 are in agreement with a previously described trend, the largest blue-shift being found for the eight-coordinate complex 7 . 


\section{Introduction}

Citric acid (2-hydroxy-1,2,3-propanetricarboxylic acid, $\mathrm{H}_{4}$ cit) is a naturally occurring complexant whose behaviour towards uranyl and other actinide cations is of relevance for nuclear waste management as well as soil remediation or decorporation studies. ${ }^{[1]}$ Uranyl speciation in solution in the presence of citric acid, which directly affects uranium mobility and availability, has consequently been the subject of many reports using a wealth of different techniques. ${ }^{[2]}$ The presence of four functional groups, some or all of which can be deprotonated depending on the solution $\mathrm{pH}$, and which can act as potentially bridging coordination sites (possibly in heterometallic species) makes this a system of great complexity. It has been found earlier that the 2:2 dimeric species $\left\{\left[\mathrm{UO}_{2}(\mathrm{Hcit})\right]_{2}\right\}^{2-}$, with coordination through both carboxylate and bridging hydroxyl groups, was the dominant solution species for $\mathrm{pH}$ values in the range of $\sim 2-5 .{ }^{[2 b, 2 d, 2 e, 2 \mathrm{~g}]}$ Although crystallographic characterization of uranyl citrate complexes lagged behind solution studies for long, a number of crystal structures have been reported in the last ten years, ${ }^{[3-12]}$ with several different polymeric assemblies evidencing the potential of citric acid for the building of uranyl-organic coordination polymers or frameworks. ${ }^{[13]}$ A 2:2 dimeric species, with the hydroxylic and two carboxylic groups being deprotonated and involving two chelate rings, fiveand six-membered, around each metal centre, has indeed been found in several cases (Scheme 1). ${ }^{[4-7,9,10,12]}$ In the complexes in which the third carboxylic acid group, not involved in the formation of the dimer, retains its proton, these dimers have been found to be isolated, ${ }^{[4,5,12]}$ or assembled into one-dimensional (1D) polymeric chains with carboxylate-bridged dimeric units. $^{[5,10]}$ When the third carboxylic group is also deprotonated, further coordination to 


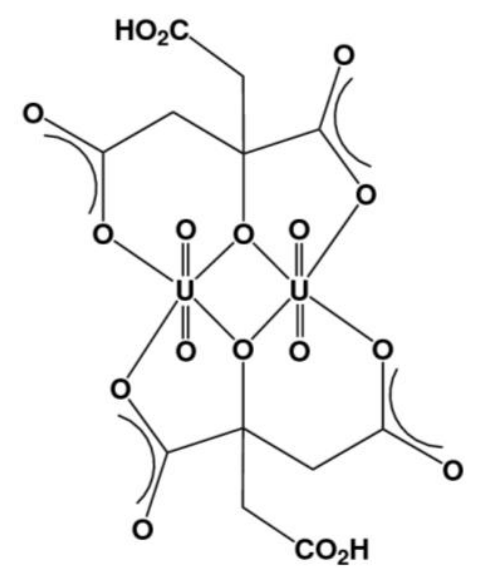

Scheme 1. The dianionic 2:2 uranyl citrate dimer involving deprotonation of the hydroxyl group and two of the three carboxylic acid groups.

additional uranyl cations gives rise to formation of two-dimensional (2D) networks ${ }^{[6,9]}$ or threedimensional (3D) frameworks. ${ }^{[7]}$ In other instances, 3D frameworks devoid of the dimeric motif have been found, ${ }^{[3,8]}$ one of them displaying oxo-bonding between uranyl cations. ${ }^{[8]}$ Although the typical dimeric motif may be retained in the presence of additional, non-uranyl metal cations, ${ }^{[4,10]}$ it has been shown recently that higher oligomers can be obtained through assembly of $\mu_{3}$-oxocentered trimers around sodium cations, ${ }^{[12]}$ and that heterometallic species involving $\mathrm{Al}^{\mathrm{III}}$ or Fe ${ }^{\mathrm{III}}$ display a different connectivity, with the deprotonated hydroxyl group as a bridge between uranyl and the other metal cation. ${ }^{[11]}$

The present work is an extension of our previous investigation of citrate complexation to uranyl under solvo-hydrothermal conditions and in the presence of additional metal cations and/or coligands, ${ }^{[4,7,9,10]}$ which is here expanded to related polycarboxylic acids with a reduced number of complexation sites: malic (2-hydroxybutanedioic, $\mathrm{H}_{3} \mathrm{ml}$ ) and citramalic (2-hydroxy-2methylbutanedioic, $\mathrm{H}_{3} \mathrm{Cml}$ ) acids, in which one of the $-\mathrm{CH}_{2}-\mathrm{COOH}$ groups of citric acid is replaced by a hydrogen atom or a methyl group, respectively, and which are thus chiral, and tricarballylic 
(propane-1,2,3-tricarboxylic, $\mathrm{H}_{3}$ tca) acid, in which the hydroxyl group is replaced by a hydrogen atom. Note that in recognition of the possibility of deprotonation of hydroxyl as well as carboxylic acid groups, we have designated malic, citramalic and citric acids by the abbreviations $\mathrm{H}_{3} \mathrm{ml}$, $\mathrm{H}_{3} \mathrm{Cml}$ and $\mathrm{H}_{4} \mathrm{cit}$, respectively, rather than by the conventional forms indicating just the number of carboxylic acid protons. Anions derived from malic, citramalic and tricarballylic acids are ligands which, like citrate, have a variety of possible chelating and bridging modes but ones which are a limited set of those possible for citrate. For chelation alone, the ring size can in principle vary from eight-membered for citrate and tricarballylate to four-membered for all, although for $\mathrm{O}$-donors to the large uranyl ion, it is expected that small rings should be favoured, ${ }^{[14]}$ and indeed dihapto coordination of carboxylate units is a common but not exclusive feature of known structures. Formation of a five-membered chelate ring involving alkoxide- and carboxylate-O donors is of course seen in the citrate dimers referred to above but it is excluded as a possibility with tricarballylate. One of our objectives in the present work was to explore further the coordination modes adopted by these versatile ligands. Several uranyl malate complexes have previously been characterized, in which either a 2:2 dimeric motif analogous to that found with citrate is present, with additional metal cations providing formation of 2D or 3D assemblies in some cases, ${ }^{[10,15]}$ or a more intricate uranyl oligomer resulting from hydrolysis as a central core. ${ }^{[16]}$ Citramalic acid, used as its pure $R$ enantiomer, has also given several complexes based on the dimeric motif, ${ }^{[5,9,10]}$ or with a different bonding mode enabling formation of a 2D network. ${ }^{[6]}$ Tricarballylic acid has always been found up to now to bind to uranyl in a four-membered ring, $\kappa^{2} O, O^{\prime}$ tris-chelating mode generating 2D networks with honeycomb topology, the presence of different additional cations resulting in shape modifications and eventual folding into a nanotube. ${ }^{[3,17]}$ Reported 
herein are seven complexes involving these four related ligands which have been characterized by their crystal structure and, for some of them, by their emission spectrum in the solid state, and which crystallize as 1D, 2D or 3D assemblies.

\section{Results and Discussion}

\section{Syntheses}

All seven complexes were synthesized under either purely hydrothermal ( 3 and $\mathbf{7}$ ) or solvohydrothermal conditions $\left(140{ }^{\circ} \mathrm{C}\right.$, autogenous pressure), the organic cosolvent in the latter cases being $N$-methyl-2-pyrrolidone (1 and 2 ) or acetonitrile (4-6). Only in complex $\mathbf{1}$ is the solvent retained in the final compound as a coligand, as is frequently observed with $N M P{ }^{[18]}$ and which possibly reflects its resistance to hydrolysis under solvothermal conditions. Complexes $\mathbf{1}$ and $\mathbf{2}$, both involving the malate ligand, also include oxalate anions formed in situ as coligands. Formation of oxalate anions during experiments performed under (solvo-)hydrothermal conditions is a frequent occurrence, ${ }^{[19]}$ but the reaction pathway has only been elucidated in some specific cases. ${ }^{[20]}$ Given the presence of nitrate anion and protons released by coordination of the acid, the most obvious possible reason for the presence of oxalate in complexes $\mathbf{1}$ and $\mathbf{2}$ is the oxidation of malic acid by nitric acid. Assuming the intermediacy of oxaloacetic acid as a result of conversion of the secondary alcohol unit to a carbonyl group, this is not a pathway available for citramalic or citric acid but is certainly known to lead to oxalate under enzymatic catalysis. ${ }^{[21]}$ Complexes $\mathbf{1}$ and $\mathbf{2}$ were synthesized from the racemic form of malic acid, and the crystal structures show the presence of both enantiomers (the crystals being centrosymmetric and, further, a disordered superposition of the two enantiomers being observed in complex 1). In 
contrast, complexes $\mathbf{3}$ and $\mathbf{4}$ were synthesized from pure $R$-citramalic acid and retain its enantiomeric purity, indicating that no racemization occurs under the conditions used, although racemization has previously been found to occur in one case under analogous conditions. ${ }^{[5]}$

While complex 1 is a case in which only two coligands (oxalate and NMP) are present, all the other complexes include additional metal cations, $\mathrm{Cu}^{\prime \prime}$ in $\mathbf{2}, \mathrm{Ni}^{\prime \prime}$ in $\mathbf{3}, \mathrm{Cd}^{\prime \prime}$ in $\mathbf{4}$ and $\mathbf{6}, \mathrm{Zn}^{\prime \prime}$ in $\mathbf{5}$, and $\mathrm{Pb}^{\|}$in 7, these being in all cases but the last associated with organic coligands, $2,2^{\prime}$-bipyridine (bipy) in 4-6, 1,10-phenanthroline (phen) in 2, and cyclam (1,4,8,11-tetraazacyclotetradecane) in 3. It is notable that systematic attempts at crystallization were made for most polycarboxylate/additional metal cation/coligand/solvent combinations involving the components present in complexes 1-7 (except for cyclam, which was only used as its preformed complex with $\left.\mathrm{Ni}^{\prime \prime}\right)$, but use of reactants and cosolvents giving a crystalline material with one polycarboxylate were generally not successful with another polycarboxylate (the usual outcome of unsuccessful experiments being precipitation of amorphous powders or formation of no solid deposit whatsoever). This is the reason why, except in the case of complexes 4 and 6 , which both contain Cd(bipy) moieties, no two complexes involve the same additional metal cation/coligand combination.

\section{Crystal Structures}

The complex $\left[\left(\mathrm{UO}_{2}\right)_{4}\left(\mathrm{ml}_{2}\left(\mathrm{C}_{2} \mathrm{O}_{4}\right)(\mathrm{NMP})_{4}\right](\mathbf{1})\right.$ crystallizes with two uranium atoms, one disordered $\mathrm{ml}^{3-}$ ligand (see Experimental Section), one centrosymmetric oxalate anion and two coordinated NMP molecules in the asymmetric unit (Figure 1). Atom U1 is chelated by two $\mathrm{ml}^{3-}$ ligands so as to form a centrosymmetric binuclear 2:2 dimer analogous to that commonly found in other uranyl 

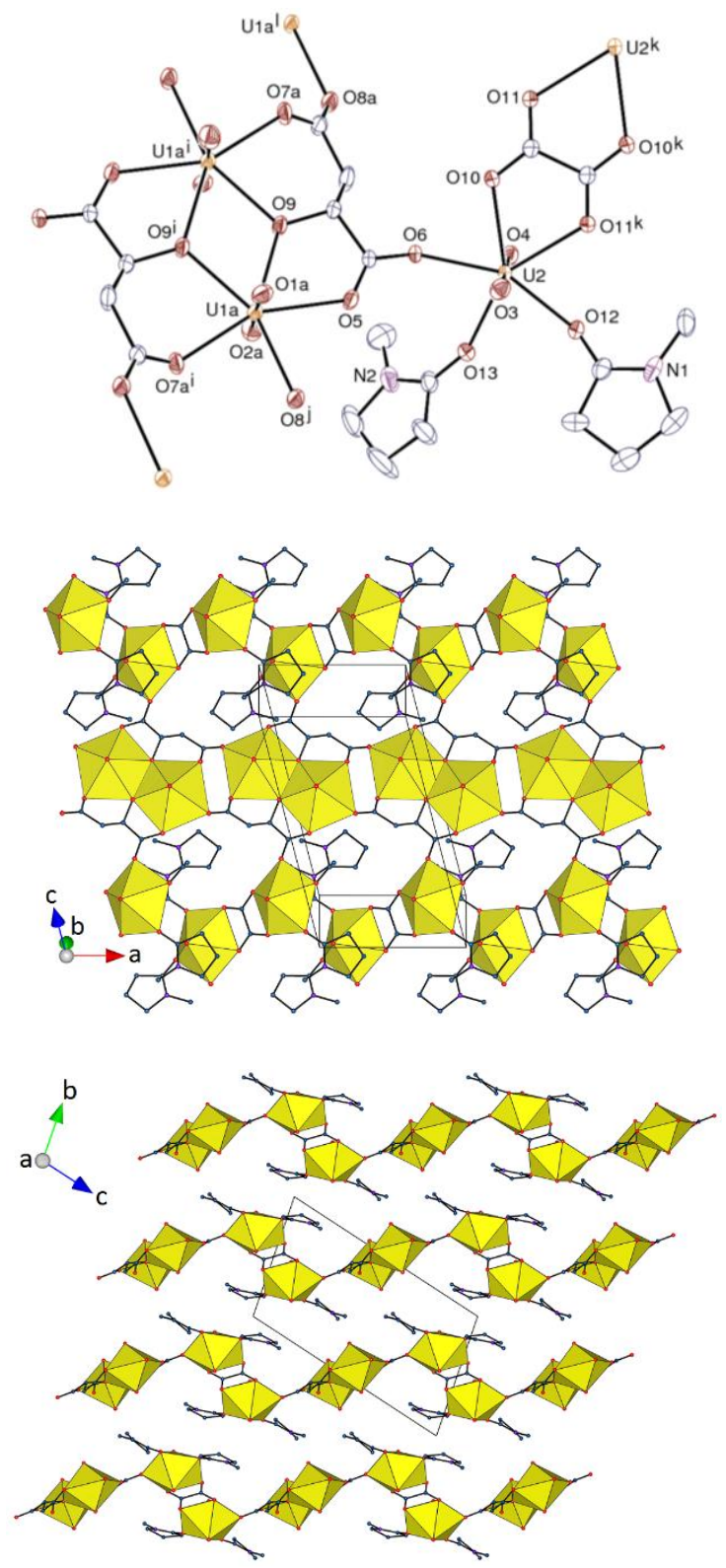

Figure 1. Top: view of complex 1. Displacement ellipsoids are drawn at the $30 \%$ probability level. Symmetry codes: $\mathrm{i}=-$ $x, 2-y, 1-z ; \mathrm{j}=x+1, y, z ; \mathrm{k}=-x-1,1-y,-z ; \mathrm{I}=x-1, y, z$. Middle: view of the 2D network with uranium coordination polyhedra colored yellow. Bottom: view of the packing with sheets viewed edge-on. Only one position of the disordered atoms is represented and hydrogen atoms are omitted in all views.

malate $^{[10,15]}$ and citrate $\mathrm{e}^{[4-7,9,10,12]}$ complexes (the crystallographic symmetry of these dimers is however variable, with the presence of an inversion centre, a twofold rotation axis, or no 
symmetry element whatever). Further bonding to a carboxylate group from another dimer giving rise to $1 \mathrm{D}$ polymerization, while atom $\mathrm{U} 2$ is bound to one chelating oxalate, one carboxylate group from a uranyl malate dimer and two NMP molecules; both uranium atoms are thus in pentagonal bipyramidal environments. The bond lengths $U-O$ (oxo) $[1.753(5)-1.821(16) \AA$, some of them possibly affected by disorder], U-O(carboxylate) [2.337(4)-2.453(4) Å], U-O(alkoxide) [2.326(5)2.427(5) $\AA$ ] , and U-O(NMP) [2.341(4) and 2.354(5) $\AA]$ are in the usual ranges. In particular, the UO(NMP) bond lengths for the 15 occurrences reported in the Cambridge Structural Database (CSD, version $5.38^{[22]}$ ) are in the range of $2.30-2.41 \AA$ [average value $\left.2.36(3) \AA ̊\right]$. The structure thus appears to contain different malate- and oxalate-bridged dinuclear units. The former are linked to give a $1 \mathrm{D}$ polymer directed along the $a$ axis through bridging $\mu_{2}-\kappa^{1} O: \kappa^{1} O^{\prime}$-carboxylate groups, and these chains are assembled into a 2D network parallel to $\left(\begin{array}{lll}0 & 1 & 1\end{array}\right)$ by $\kappa^{1}$ coordination of $\mathrm{O} 6$ to U2 of the latter oxalate-bridged moieties, the angle between the two different subunits resulting in the network sheet having a sawtooth shape when viewed down the $a$ axis. The approximately coplanar NMP molecules are located on the sides of the sheets, and examination of the Hirshfeld surface $(\mathrm{HS})^{[23]}$ calculated on the asymmetric unit with CrystalExplorer ${ }^{[24]}$ does not reveal significant interactions beyond dispersion, apart from some possible weak inter-layer $\mathrm{CH} \cdots \mathrm{O}$ hydrogen bonds. ${ }^{[25]}$ The packing does not provide solvent-accessible free spaces, as indicated by the Kitaigorodski packing index (KPI, estimated with PLATON ${ }^{[26]}$ ) of $\sim 0.67$.

The complex $\left[\left(\mathrm{UO}_{2}\right)_{2} \mathrm{Cu}_{2}(\mathrm{ml})_{2}\left(\mathrm{C}_{2} \mathrm{O}_{4}\right)(\text { phen })_{2}\right]$ (2) crystallizes with one uranyl cation, one $\mathrm{Cu}(\mathrm{phen})$ group, one malate ligand of either $R$ or $S$ configuration, and one centrosymmetric oxalate anion in the asymmetric unit (Figure 2), and it thus derives from 1 by replacement of the $\mathrm{UO}_{2}(\mathrm{NMP})_{2}$ with the $\mathrm{Cu}(\mathrm{phen})$ moiety. The uranyl malate unit forms a centrosymmetric 2:2 dimer analogous to 

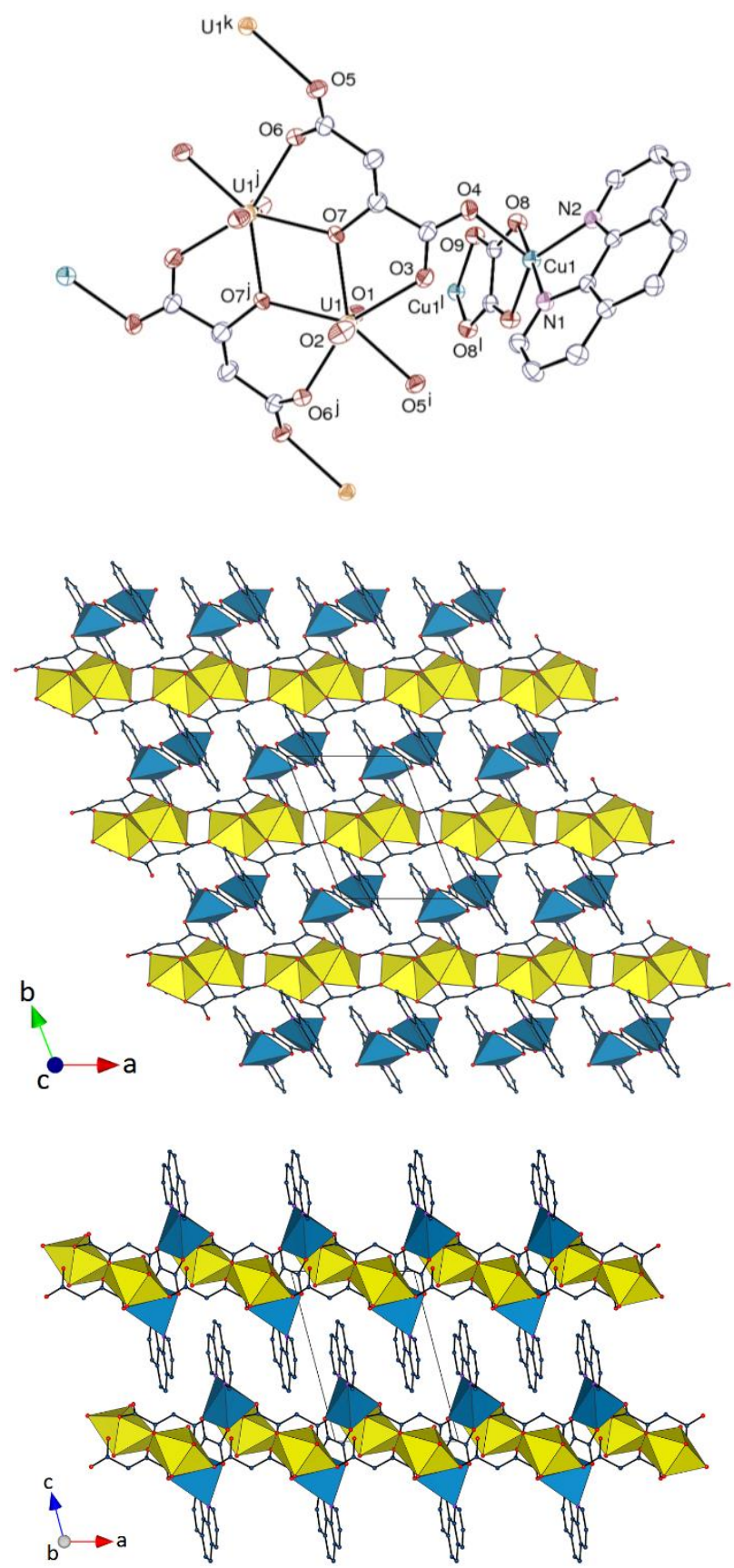

Figure 2. Top: view of complex 2. Displacement ellipsoids are drawn at the $30 \%$ probability level. Symmetry codes: $\mathrm{i}$ $=x-1, y, z ; \mathrm{j}=1-x, 1-y,-z ; \mathrm{k}=x+1, y, z ; \mathrm{I}=-x,-y,-z$. Middle: view of the $2 \mathrm{D}$ network with uranium coordination polyhedra colored yellow and those of copper blue. Bottom: view of the packing with sheets viewed edge-on. Hydrogen atoms are omitted in all views. 
that in 1 except for the absence of disorder, both ligand enantiomers being present in each centrosymmetric dimer. The coordination bond lengths are unexceptional [U-O(oxo) 1.765(4) and

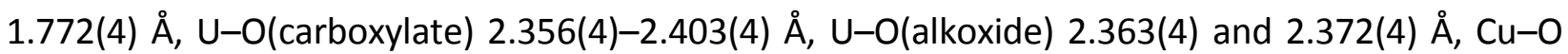
1.946(3)-2.259(5) $\AA$, and $\mathrm{Cu}-\mathrm{N} 1.969(4)$ and 2.018(4) $\AA$ ]. The copper(II) ion is in a distorted square pyramidal environment, with the most distant donor (the malate carboxylate atom 04 ) in the apical position. Here also, carboxylate bridging of uranyl cations (through the $-\mathrm{CH}_{2}-\mathrm{COO}^{-}$group) assembles the dimers into a 1D polymer directed along the $a$ axis, and the oxalate-bridged copper dinuclear units link the chains through copper bonding to the other carboxylate group to form a 2D network parallel to $\left(\begin{array}{lll}0 & 0 & 1\end{array}\right)$. The role played by the $[\mathrm{Cu}(\text { phen })]_{2}\left(\mathrm{C}_{2} \mathrm{O}_{4}\right)^{2+}$ moiety is thus exactly the same as that of $\left[\mathrm{UO}_{2}(\mathrm{NMP})_{2}\right]_{2}\left(\mathrm{C}_{2} \mathrm{O}_{4}\right)^{2+}$ in 1 . However, the sheets here are planar, with the phen molecules pointing outward on the two sides, so that interdigitation occurs in the packing. Analysis of short contacts with PLATON ${ }^{[26]}$ indicates that five possible parallel-displaced $\pi$-stacking interactions may be present between adjacent phen molecules, with centroid $\cdots$ centroid distances in the range of 3.738(4)-3.965(4) $\AA$ and dihedral angles of $0-1.2(3)^{\circ}$. However, they do not appear prominently on the $\mathrm{HS}$, which reveals the presence of several $\mathrm{CH}$ (phen) $\cdots O$ hydrogen bonds, both intra- and inter-layer, involving uranyl oxo or carboxylato acceptors [C $\cdots$ O distances 3.170(7)3.474(7) $\AA, \mathrm{H} \cdots \mathrm{O} 2.42-2.52 \AA, \mathrm{C}-\mathrm{H} \cdots \mathrm{O}$ angles $\left.134-178^{\circ}\right]$. These interactions appear as red dots on the HS (Figure 3), which correspond to distances shorter than the sum of van der Waals radii (the blue coloration indicating the absence of such contacts). With a KPI of 0.69 , the packing does not contain solvent-accessible voids. 


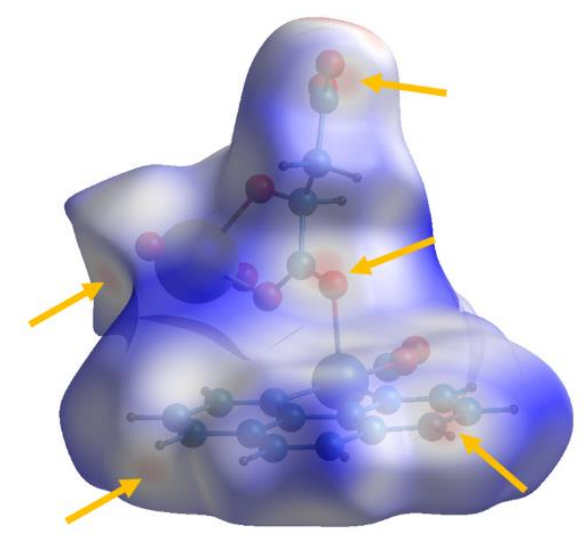

Figure 3. Hirshfeld surface mapped with $d_{\text {norm }}$ calculated on the asymmetric unit of complex 2 . The red spots indicated by arrows correspond to the positions of $\mathrm{CH} \cdots \mathrm{O}$ hydrogen bonds. The large red dot at the top is due to truncation of the polymer chain.

Complex 3, $\left[\left(\mathrm{UO}_{2}\right)_{2} \mathrm{Ni}(\mathrm{cml})_{2}(\mathrm{cyclam})\right]$, contains the pure $R$ enantiomer of the citramalate ligand and it crystallizes in the Sohncke group $P 1$. The asymmetric unit contains two uranyl ions, two fully deprotonated $\mathrm{cml}^{3-}$ ligands and one $\mathrm{Ni}(\text { cyclam) })^{2+}$ moiety (Figure 4). As in some of the previously reported uranyl complexes with this ligand, ${ }^{[5,9,10]}$ a $2: 2$ dimer is formed, which, in contrast to those in $\mathbf{1}$ and $\mathbf{2}$, is devoid of crystallographic symmetry (and both methyl groups are pointing toward the same side of the dimer). The $\mathrm{Ni}(\text { cyclam })^{2+}$ cation is a very well known species, being present in 162 structures reported in the CSD, and its configuration here, identical to that in the first ever structural determination, ${ }^{[27]}$ is the minimum energy one, designated as RRSS Trans III. ${ }^{[28]}$ The nickel(II) cation is further bound to two more distant axial carboxylate oxygen atoms, its environment being elongated octahedral, the macrocyclic ligand thus enforcing a role as a linear bridge. The bond lengths are as usual $[\mathrm{U}-\mathrm{O}(\mathrm{oxo}) 1.70(3)-1.834(18) \AA$, U-O(carboxylate)

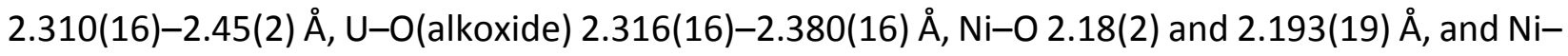
N 2.04(2)-2.07(2) Å]. In this case also, carboxylate bridging insures linear polymerization along 

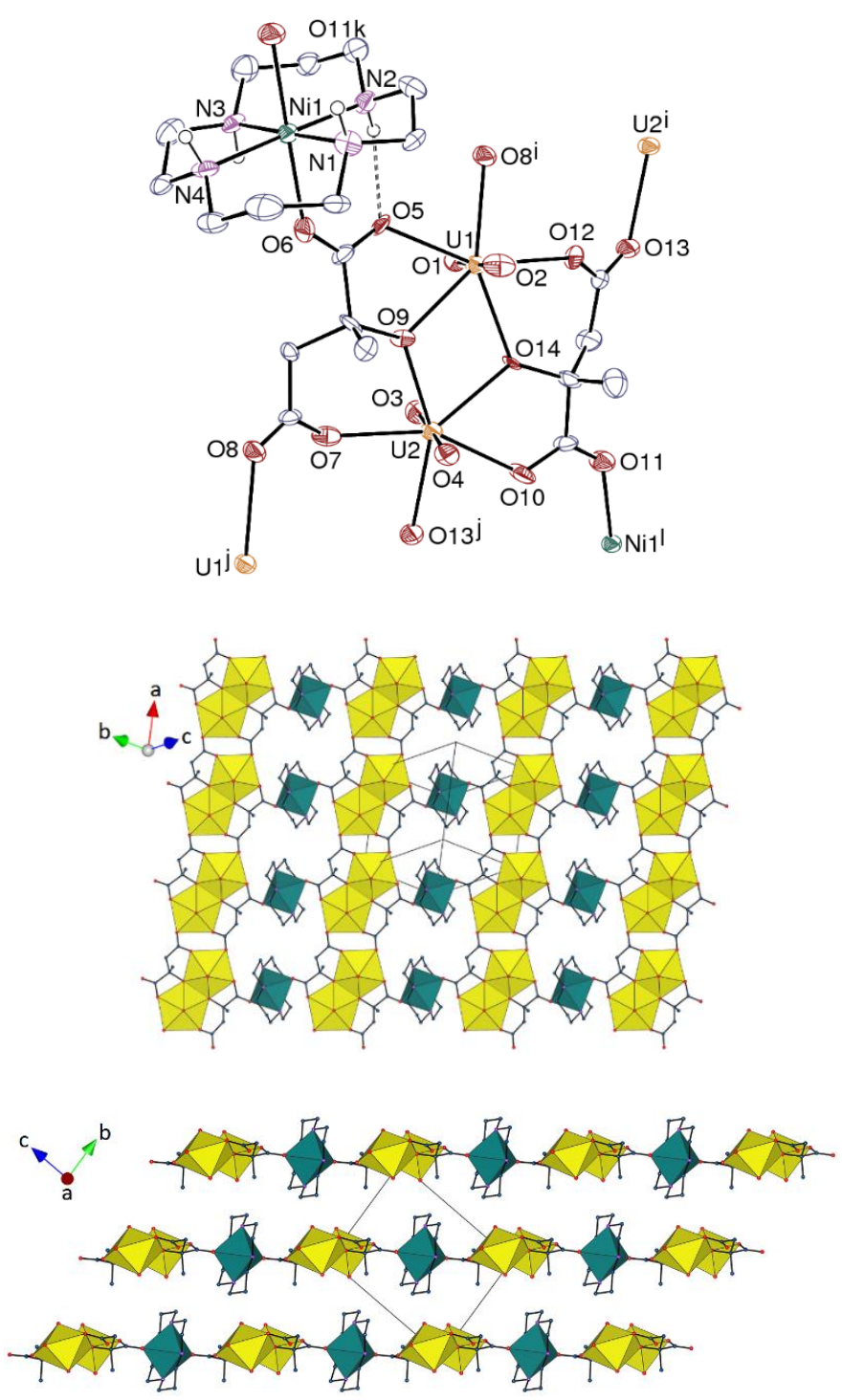

Figure 4. Top: view of complex 3. Displacement ellipsoids are drawn at the $40 \%$ probability level. Carbon-bound hydrogen atoms are omitted and the hydrogen bond is shown as a dashed line. Symmetry codes: $\mathrm{i}=x-1, y, z ; \mathrm{j}=x$ $+1, y, z ; k=x, y+1, z-1 ; I=x, y-1, z+1$. Middle: view of the 2D network with uranium coordination polyhedra colored yellow and those of nickel green. Bottom: view of the packing with sheets viewed edge-on. Hydrogen atoms are omitted in the last two views.

the $a$ axis, and $\mathrm{Ni}(\text { cyclam })^{2+}$ units assemble the chains into a 2D net parallel to $\left(\begin{array}{lll}0 & 1 & 1\end{array}\right)$. Three coordinated NH groups of cyclam are hydrogen bonded to oxo or carboxylato oxygen atoms [ $\mathrm{N} \cdots \mathrm{O}$ 
distances 2.83(3)-3.12(3) $\AA, \mathrm{H} \cdots \mathrm{O} 2.04-2.61 \AA$, $\mathrm{N}-\mathrm{H} \cdots \mathrm{O}$ angles $112-149^{\circ}$ ]. As in complexes 1 and 2, the HS shows only the possible presence of weak intra- and inter-layer $\mathrm{CH} \cdots \mathrm{O}$ hydrogen bonds involving hydrogen atoms from cyclam molecules and oxo or carboxylato acceptors [C...O distances 3.14(3)-3.42(3) $\AA$, H $\cdots 0$ 2.47-2.65 $\AA, \mathrm{C}-\mathrm{H} \cdots \mathrm{O}$ angles $114-138^{\circ}$ ]. The packing is compact, with a KPI of 0.67.

Complex 4, $\left[\left(\mathrm{UO}_{2}\right)_{2} \mathrm{Cd}(\mathrm{cml})_{2}(\right.$ bipy $\left.)\left(\mathrm{H}_{2} \mathrm{O}\right)_{2}\right]$, which crystallizes in the monoclinic Sohncke group $P 2_{1}$, has an asymmetric unit much larger than that in $\mathbf{3}$, with six uranyl cations, three $\mathrm{Cd}(\text { bipy })^{2+}$ moieties, and six $R$ - $\mathrm{cml}^{3-}$ ligands (Figure 5). Three 2:2 uranyl dimers analogous to that in $\mathbf{3}$ are thus present, while the cadmium(II) cations, in octahedral environments, are chelated by one bipy molecule and bound to two trans carboxylate oxygen atoms and two cis water molecules, thus being achiral centres. The bond length ranges are unexceptional [U-O(oxo) 1.760(12)-1.794(12) Å, U-O(carboxylate) 2.376(11)-2.425(9) ̊̊, U-O(alkoxide) 2.345(11)2.376(10) $\AA$, Cd-O 2.229(10)-2.282(12) A, and Cd-N 2.328(16)-2.363(15) $\AA$ ]. As in complexes 13, each dimer is connected to four additional metal atoms, here two uranium (through the $-\mathrm{CH}_{2}-$ $\mathrm{COO}^{-}$groups) and two cadmium atoms, but, in contrast to previous cases, the three dimers of the asymmetric unit being far from coplanar, the assembly formed by citramalate and uranyl ions alone is not a 1D polymer, but a uninodal 3D framework with the point (Schläfli) symbol $\left\{4.12^{2}\right\}$ and the chiral qtz-h topology. ${ }^{[29]}$ Cadmium bridges are thus not essential to framework building and they add no extra aspect of chirality to be considered, but the bipy ligands may have a structure-directing effect, as suggested by their location in the channels with a roughly triangular section that run along the $a$ axis. The voids in the uranyl citramalate framework are thus occupied, 

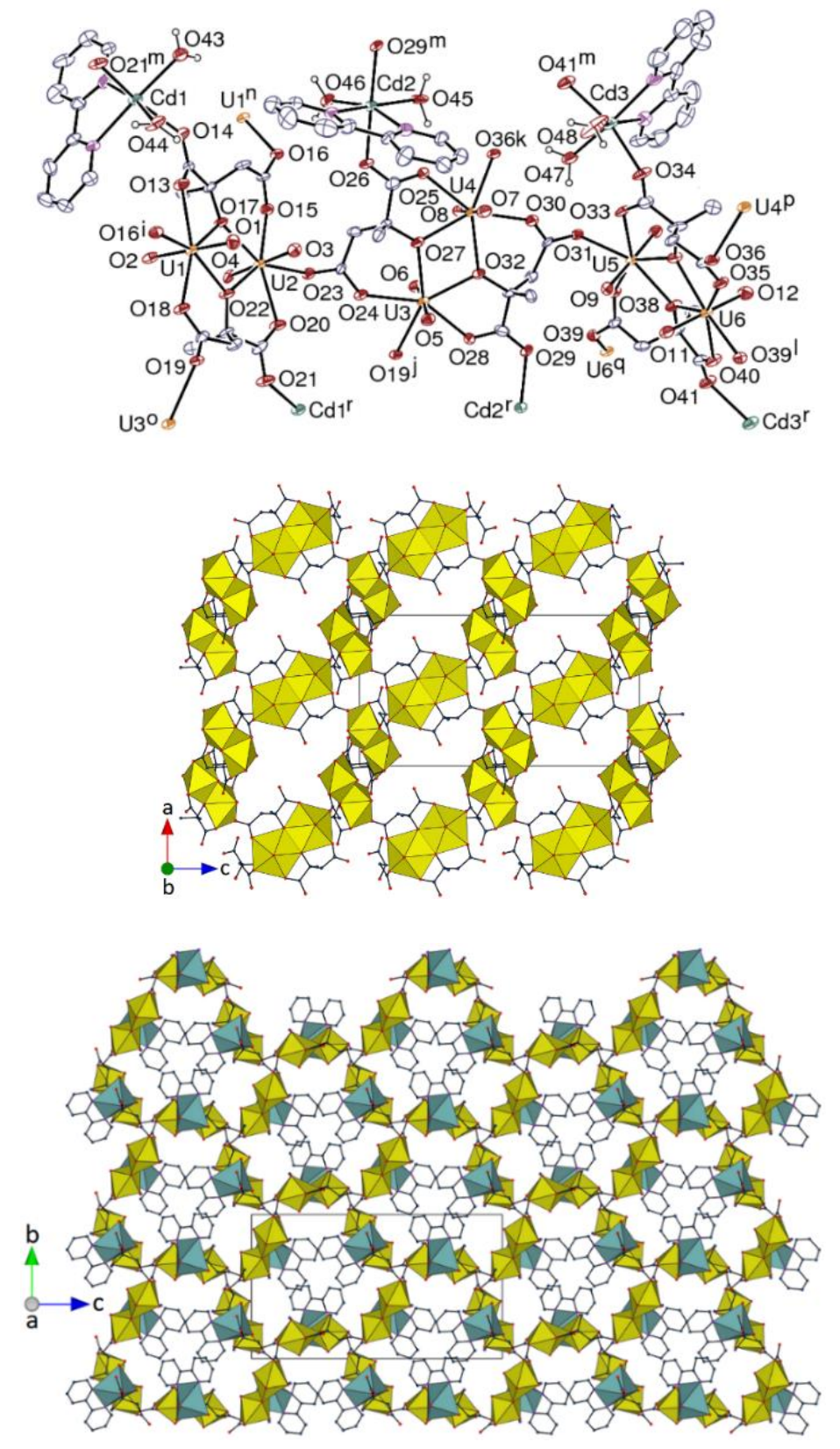

Figure 5. Top: view of complex 4. Displacement ellipsoids are drawn at the $30 \%$ probability level and carbon-bound hydrogen atoms are omitted. Symmetry codes: $\mathrm{i}=-x, y+1 / 2,1-z ; \mathrm{j}=1-x, y-1 / 2,1-z ; \mathrm{k}=1-x, y-1 / 2,-z ; \mathrm{I}=2$ $-x, y+1 / 2,-z ; m=x-1, y, z ; n=-x, y-1 / 2,1-z ; 0=1-x, y+1 / 2,1-z ; p=1-x, y+1 / 2,-z ; q=2-x, y-1 / 2,-z$ $r=x+1, y, z$. Middle: view of the uranyl citramalate anionic 3D framework. Bottom: view of the complete 3D framework. Uranium coordination polyhedra are colored yellow and those of cadmium green, and hydrogen atoms are omitted. 
as indicated by the $\mathrm{KPI}$ of 0.63 . The bipy molecules are located with respect to one another in a way that does not enable $\pi$-stacking interactions, the distances between centroids being larger than $5.8 \AA ̊$. The water ligands are hydrogen bonded to carboxylate oxygen atoms [O $\cdots 0$ distances

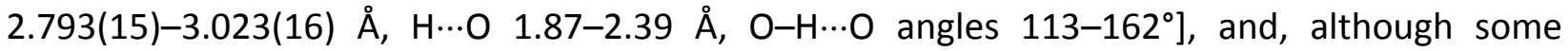
$\mathrm{CH}$ (bipy) $\cdots \mathrm{O}$ hydrogen bonds can be discerned, they are seemingly less prominent than their counterparts in $\mathbf{2}$.

The citrate complex $\left[\left(\mathrm{UO}_{2}\right)_{2} \mathrm{Zn}(\mathrm{Hcit})_{2}(\text { bipy })_{2}\left(\mathrm{H}_{2} \mathrm{O}\right)\right](5)$ is isomorphous to its $\mathrm{Ni}$-containing counterpart, which has been previously reported, ${ }^{[10]}$ so that only a brief description will be given here. The usual 2:2 uranyl citrate dimer is assembled into 1D polymeric chains running along the $c$ axis, but, since only one $\mathrm{Zn}$ (bipy) $2^{2+}$ group is appended to each dimer (one of the carboxylate groups being monodentate instead of bridging), the chains are not assembled into a higher dimensionality unit and the terminal $\mathrm{Zn}\left(\right.$ bipy $2_{2}{ }^{2+}$ moieties are mere decorating groups (Figure 6). The bond lengths are in the usual ranges [U-O(oxo) 1.771(5)-1.785(5) $\AA$, U-O(carboxylate)

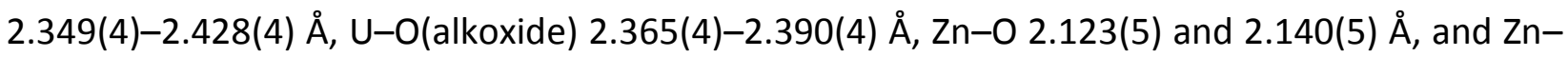
N 2.099(6)-2.162(6) Å]. The zinc(II) cation is in an octahedral environment, its water ligand being hydrogen bonded to carboxylate oxygen atoms in the same and a neighbouring chain. Unlike the $\mathrm{Cd}^{\text {"l }}$ centre in complex 4, the $\mathrm{Zn}$ " centre here is chiral and along one side of the 1D uranyl polymer, the $\mathrm{Zn}$ " centres are of the same chirality but opposite to that of the $\mathrm{Zn}$ " centres on the other side. This feature is in fact allied to another concerning the bound citrate units and involving some parallel with both the malate and citramalate complex structures. Thus, when the two $-\mathrm{CH}_{2}-$ $\mathrm{COO}(\mathrm{H})$ units of citrate are differentiated by their bonding interactions, citrate itself becomes a 

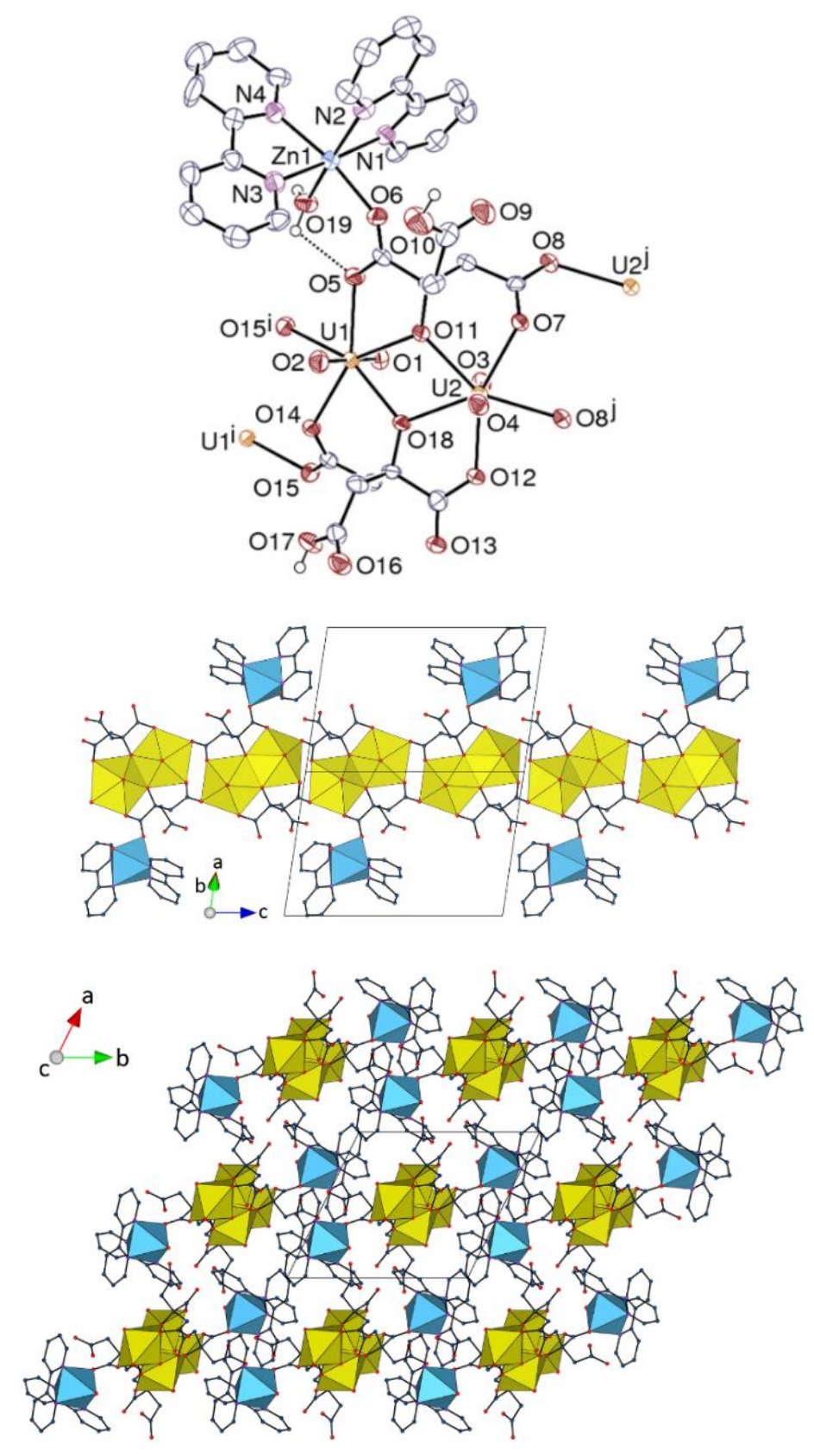

Figure 6. Top: view of complex 5. Displacement ellipsoids are drawn at the 50\% probability level. Carbon-bound hydrogen atoms are omitted and the hydrogen bond is shown as a dashed line. Symmetry codes: $\mathrm{i}=1-x, 1-y,-z ; \mathrm{j}$ $=1-x, 1-y, 1-z$. Middle: view of the 1D chain with uranium coordination polyhedra colored yellow and those of zinc blue. Bottom: view of the packing with chains viewed end-on. Hydrogen atoms are omitted in the last two views. 
chiral species. This is apparent in $\left[\left(\mathrm{UO}_{2}\right)_{3}(\mathrm{Hcit})_{2}\left(\mathrm{H}_{2} \mathrm{O}\right)_{3}\right] \cdot 2 \mathrm{H}_{2} \mathrm{O}$, which crystallizes in the Sohncke space group $P 2{ }_{1} 2{ }_{1} 2{ }_{1}{ }^{3}$ In the $1 D$ polymer of 5 , where inequivalent uranium centres, U1 and U2, can be considered as providing a repeat unit of U1-U2-U2-U1, adjacent U1U2 units are bridged by citrate ligands (both involving alkoxide-O) of the same chirality, whereas both U1U1 and U2U2 pairs are bridged (through carboxylate-O atoms only) by citrate units of opposite chirality. Along the chain, the chirality of the U1U2 bridges alternates and, as one $\mathrm{Zn}(\text { bipy })_{2}\left(\mathrm{H}_{2} \mathrm{O}\right)^{2+}$ unit is attached to each U1U2 pair, its chirality alternates in concert, so that $R$-citrate, for example, is associated with $\Delta \mathrm{Zn}^{\text {"l }}$. The two uncomplexed carboxylic groups contribute to inter-chain linking through hydrogen bonding to carboxylate oxygen atoms (one of them being involved in a double bond with its image by inversion) [O $\cdots$ O distances $2.642(8)$ and $2.586(7) \AA, H \cdots O 1.82$ and $1.89 \AA$, O$\mathrm{H} \cdots \mathrm{O}$ angles 162 and $148^{\circ}$ ]. These bonds are conspicuous in the HS (Figure 7), as well as several $\mathrm{CH}$ (bipy) $\cdots$ O hydrogen bonds.

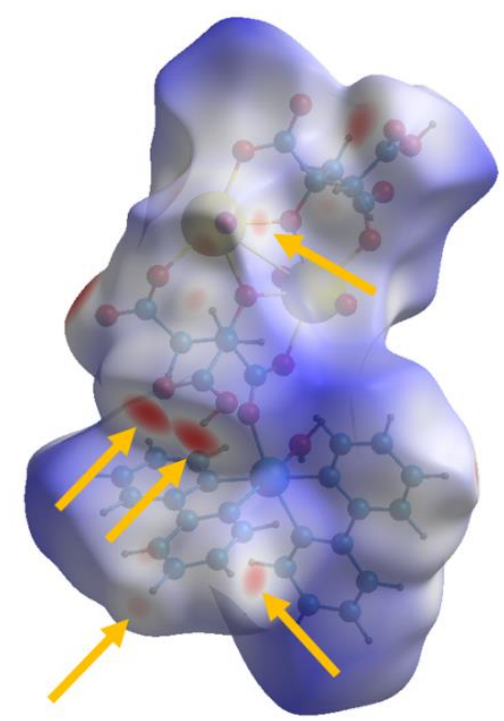

Figure 7. Hirshfeld surface mapped with $d_{\text {norm }}$ calculated on the asymmetric unit of complex $\mathbf{5}$. The red spots indicated by arrows correspond to the positions of $\mathrm{OH} \cdots \mathrm{O}$ (between carboxylic groups, near the centre of the $\mathrm{HS}$ ) and $\mathrm{CH} \cdots \mathrm{O}$ hydrogen bonds. 
The complex $\left[\left(\mathrm{UO}_{2}\right)_{2} \mathrm{Cd}(\mathrm{Hcit})_{2} \text { (bipy) }\right)_{2}$ (6) constitutes an interesting variation on the

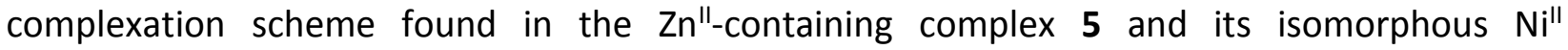
counterpart. The asymmetric unit in 6 contains a uranyl citrate centrosymmetric dimer, meaning that both bound citrate units are of the same chirality (see above) and one highly disordered, chiral Cd(bipy) ${ }^{2+}$ moiety (see Experimental Section) (Figure 8). As in 5, the dimer is bound to only
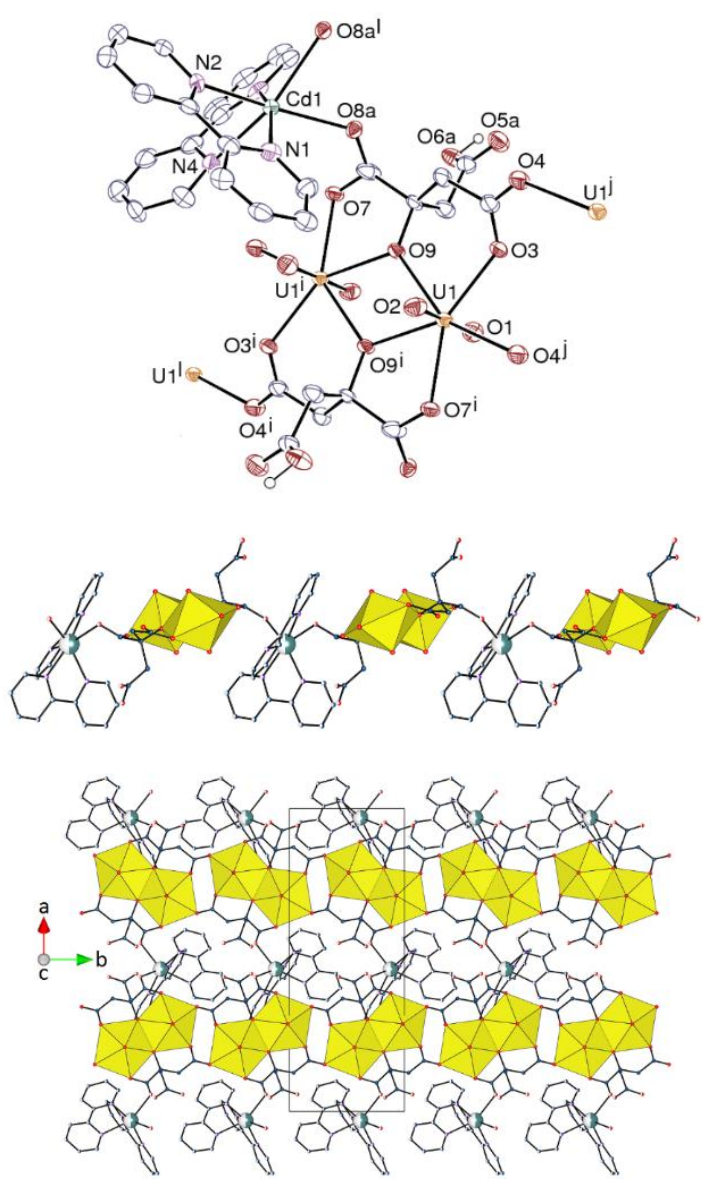

Figure 8. Top: view of complex 6. Displacement ellipsoids are drawn at the $40 \%$ probability level. Only one position of the disordered parts is represented and carbon-bound hydrogen atoms are omitted. Symmetry codes: $i=3 / 2-x$, $1 / 2-y,-z ; j=3 / 2-x,-y-1 / 2,-z ; I=2-x, y, 1 / 2-z$. Middle: the $2 \mathrm{D}$ assembly viewed edge-on, down the $b$ axis. Bottom: the 2D assembly viewed side-on, down the $c$ axis. Uranium coordination polyhedra are colored yellow and the disordered atoms, including cadmium, are represented as parti-coloured spheres. 
three additional cations, although this is only true here on average due to disorder, two uranyl and one cadmium(II), but the water ligand bound to $\mathrm{Zn}$ " in $\mathbf{5}$ is replaced here by the image through twofold rotation of the carboxylate group bound to $\mathrm{Cd}^{\prime \prime}$, the latter being thus in an octahedral environment with two cis oxygen donors. The bond lengths are unremarkable [U-O(oxo) 1.766(4)

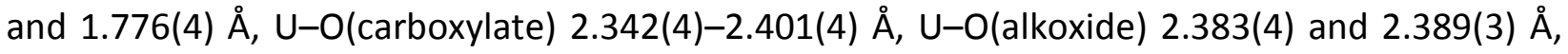
Cd-O 2.314(8)-2.486(8) $\AA$, and Cd-N 2.297(6)-2.393(6) $\AA$, the distances involving Cd being probably affected by disorder]. A 2D assembly parallel to (1 $0 \overline{1})$ is thus formed, and the carboxylic acid groups from adjacent layers are involved in double hydrogen bonding with one another, thus uniting the sheets into a hydrogen bonded framework. Further analysis of the weak interactions present is precluded by the extended disorder affecting the structure.

The last complex in this series, $\left[\left(\mathrm{UO}_{2}\right)_{2} \mathrm{~Pb}(\mathrm{tca})_{2}\left(\mathrm{H}_{2} \mathrm{O}\right)_{4}\right](7)$, involves the tricarballylate ligand, which differs from malate, citramalate and citrate by the absence of the alkoxide group. Like citrate, if the two $-\mathrm{CH}_{2}-\mathrm{COO}^{-}$groups differ in their bonding interactions, it can be considered as a chiral species but in the case of $\mathbf{7}$, the equivalence of these groups is maintained. This is not the case in other tricarballylate complexes ${ }^{3,17}$ and the unsymmetrical binding of the ligand $-\mathrm{CH}_{2}-$ $\mathrm{COO}^{-}$groups in $\left[\mathrm{UO}_{2} \mathrm{Na}(\mathrm{tca})\left(\mathrm{H}_{2} \mathrm{O}\right)_{4}\right]$ explains the formation of chiral crystals (space group $P 2{ }_{1} 2_{1} 2_{1}$ ) by this complex, ${ }^{3}$ although in $\left[\mathrm{UO}_{2} \mathrm{Ag}(\mathrm{tca})\left(\mathrm{H}_{2} \mathrm{O}\right)\right] \cdot 0.5 \mathrm{H}_{2} \mathrm{O}$ and $\left[\mathrm{NH}_{4}\right]\left[\left(\mathrm{UO}_{2}\right)_{2} \mathrm{~Pb}(\mathrm{tca})_{2}\left(\mathrm{NO}_{3}\right)(\right.$ bipy $\left.)\right]$, which have unsymmetrically coordinated carballylate in their lattices, ${ }^{17}$ the space groups are centrosymmetric, both enantiomeric forms of the ligand being present in the one lattice. Here, complex 7 crystallizes in the centrosymmetric orthorhombic space group Pnnm, and the asymmetric unit contains one uranyl cation located on a symmetry plane (Wyckoff position $4 g$ ), 
one lead(II) cation on a site with $2 / m$ symmetry $(2 a)$, one ligand with mirror symmetry, and one water molecule bound to $\mathrm{Pb}^{\prime \prime}$ (Figure 9). The uranium atom is bound to three chelating
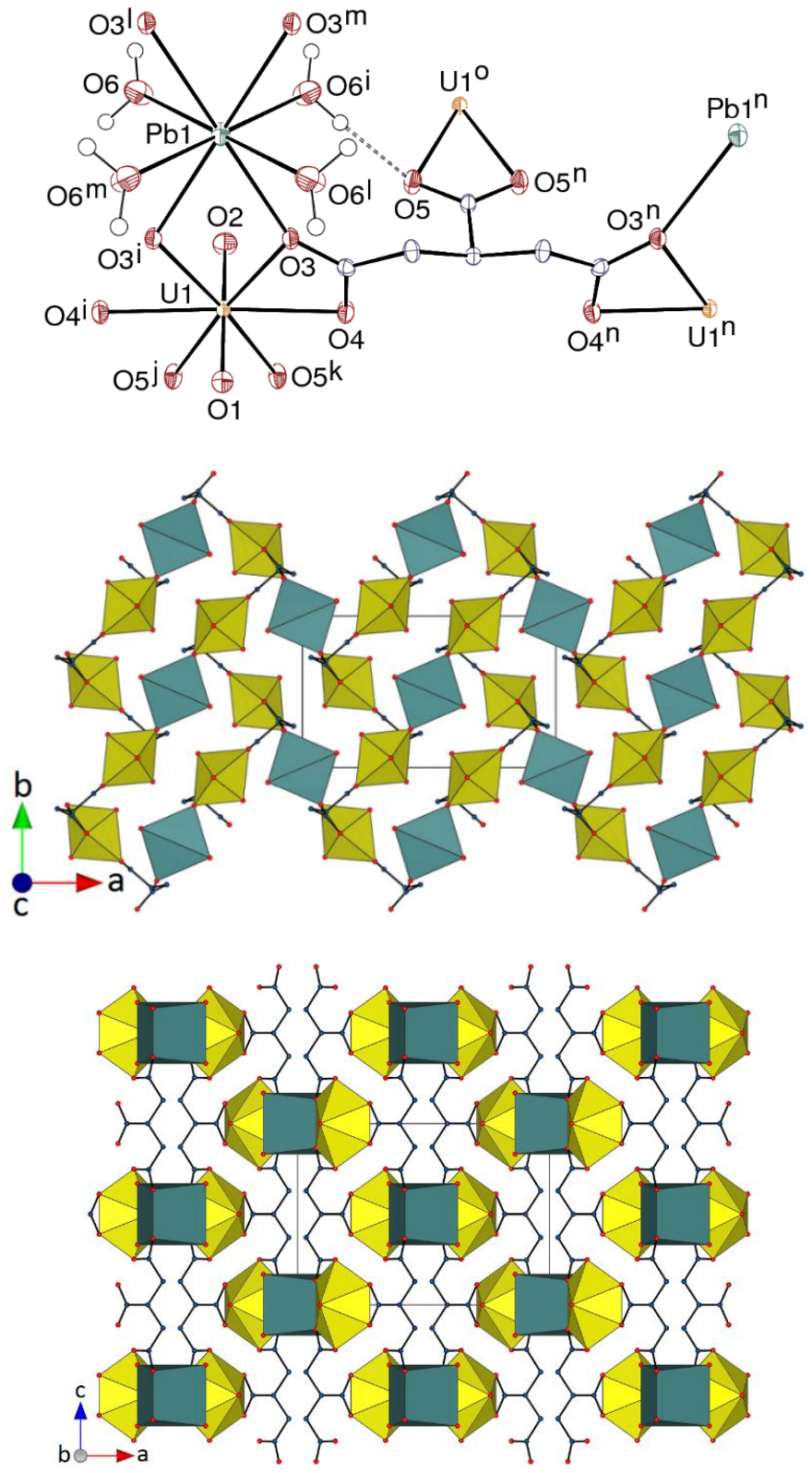

Figure 9. Top: view of complex 7. Displacement ellipsoids are drawn at the $50 \%$ probability level. Carbon-bound hydrogen atoms are omitted and the hydrogen bond is shown as a dashed line. Symmetry codes: $\mathrm{i}=x, y, 1-z ; \mathrm{j}=3 / 2$ $-x, y+1 / 2, z+1 / 2 ; \mathrm{k}=3 / 2-x, y+1 / 2,1 / 2-z ; \mathrm{I}=1-x, 1-y, 1-z ; \mathrm{m}=1-x, 1-y, z ; \mathrm{n}=x, y,-z ; 0=3 / 2-x, y-1 / 2$ $1 / 2-z$. Middle and bottom: two views of the 3D framework with uranium coordination polyhedra colored yellow and those of lead green, and hydrogen atoms omitted. 
carboxylate groups from three ligands, as usual with $\mathrm{tca}^{3-},{ }^{3,17]}$ and $\mathrm{Pb}^{\|}$is bound to four oxygen atoms from carboxylate groups bridging in $\mu_{2}-\kappa^{1} O: \kappa^{2} O, O^{\prime}$ mode, and four water molecules [U$\mathrm{O}$ (oxo) $1.766(3)$ and $1.771(3) \AA$, U-O(carboxylate) $2.459(2)-2.485(2) \AA, \mathrm{Pb}-\mathrm{O}$ (carboxylate) 2.649(2) $\AA$, and $\mathrm{Pb}-\mathrm{O}$ (water) $2.634(2) \AA]$. The eight-coordinate lead(II) cation is in a square prismatic or cubic environment, a geometry which is uncommon for this cation, ${ }^{[30,31]}$ each face containing two carboxylate and two water vertices; this environment is clearly holodirected, which is usual for lead(II) with high coordination numbers (although eight-coordination is borderline). ${ }^{[31]}$ From a topological point of view, uranium cations, lead(II) cations and tca ${ }^{3-}$ ligands are thus three-, four- and five-fold nodes, respectively, and a 3D framework is formed, which has the point symbol $\left\{4.6^{2}\right\}_{2}\left\{4^{3} \cdot 6^{7}\right\}_{2}\left\{4^{4} \cdot 6^{2}\right\}$ (for $\mathrm{U}, \mathrm{tca}^{3-}$ and $\mathrm{Pb}$, respectively). The assembly is very compact and no solvent-accessible void is found (KPI 0.75). The water molecule is hydrogen

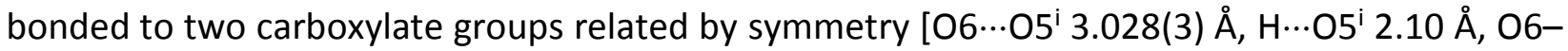

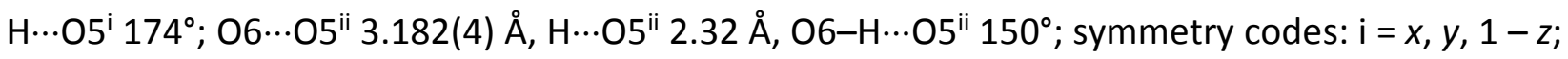
$\mathrm{ii}=3 / 2-x, y-1 / 2, z+1 / 2]$.

\section{Luminescence Properties}

The emission spectra of complexes 3-7 in the solid state were recorded at room temperature under excitation at a wavelength of $420 \mathrm{~nm}$, a value suitable for excitation of the uranyl chromophore, ${ }^{[32]}$ and they are shown in Figure 10 . The spectra display more or less intense and 


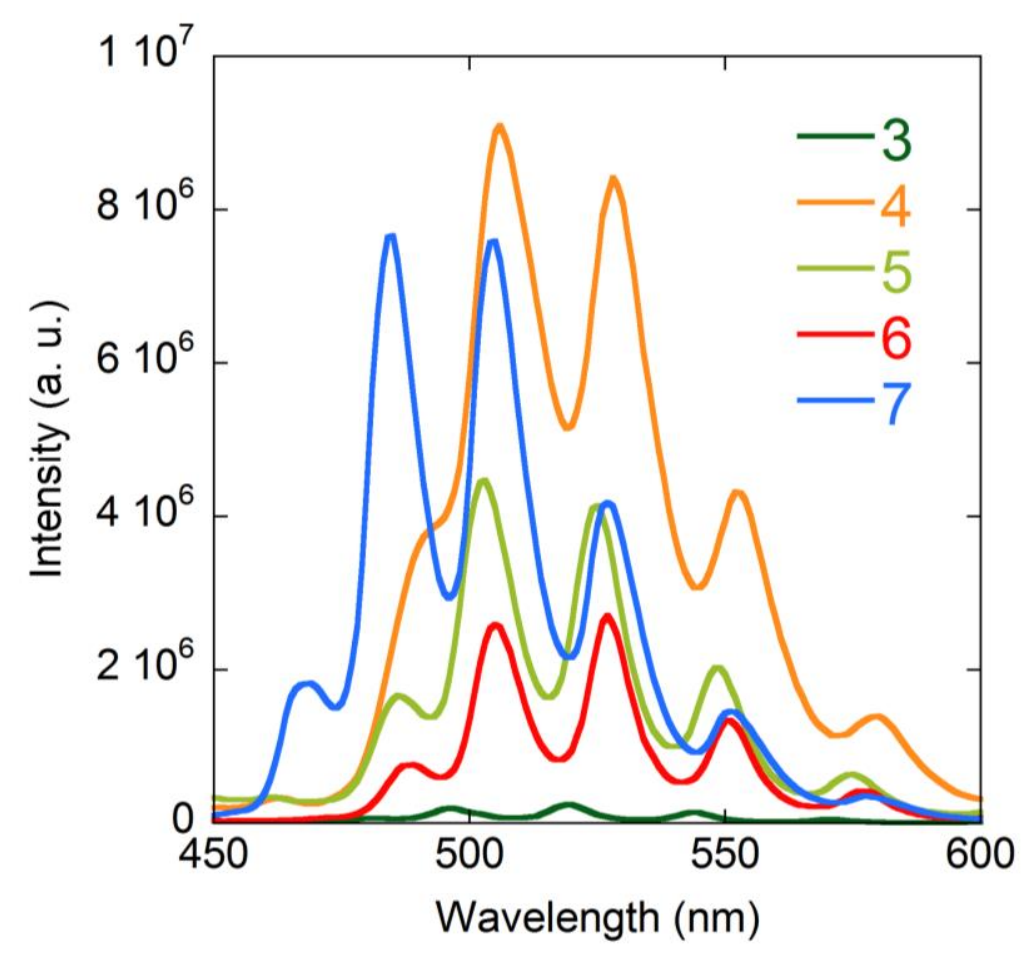

Figure 10. Solid state uranyl emission spectra of complexes 3-7, measured with an excitation wavelength of $420 \mathrm{~nm}$.

well-resolved emission peaks typical of the vibronic progression corresponding to the $S_{11} \rightarrow S_{00}$ and $S_{10} \rightarrow S_{0 v}(v=0-4)$ electronic transitions. ${ }^{[33]}$ Relatively weak emission is found for complex $\mathbf{3}$, which may be a result of partial quenching due to $\mathrm{Ni}^{l l}$ providing a nonradiative relaxation pathway. ${ }^{[34]}$ The four main emission maxima $\left(S_{10} \rightarrow S_{0 v}, v=0-3\right)$ for the seven-coordinate complexes 3-6, which all have a similar equatorial garland of three carboxylate-O and two alkoxoO donor atoms, are in the ranges $496-506,519-528,544-552$ and $571-580 \mathrm{~nm}$, thus covering a $10 \mathrm{~nm}$ wide interval (and only a $3 \mathrm{~nm}$ wide interval if only the most strongly emitting complexes 4-6 are considered), while the same maxima for the eight-coordinate complex 7 are at 485, 505, 527 and $551 \mathrm{~nm}$, i.e. blue-shifted by $\sim 10 \mathrm{~nm}$ with respect to the lowest of the previous values, and more than $20 \mathrm{~nm}$ with respect to those for 4-6. This trend is in agreement with that recently shown to exist in a series of 46 uranyl carboxylate complexes, ${ }^{[35]}$ eight-coordination (often 
involving tri-chelation by three carboxylate groups, as here) being consistently associated with the most blue-shifted values, probably due to a decrease in donor strength of the ligands in the equatorial plane inducing an increase in uranyl oxo bond order. ${ }^{[36]}$ The average vibronic splitting energy values for the $S_{10} \rightarrow S_{0 v}$ transitions in 3-6 are in the usual range of $823(4)-883(10) \mathrm{cm}^{-1}$ (the largest value being for complex 3 ). ${ }^{[33,35,37]}$

\section{Conclusions}

Apart from complex 7, in which the tricarballylate ligand displays its usual tris(chelating) mode toward uranyl, all complexes 1-6, whether they involve $R, S$-malate, $R$-citramalate or citrate anions, contain 2:2 dimers closely related in form to those which have been proposed long ago

on the basis of solution measurements, ${ }^{[2 b]}$ and characterized first by EXAFS experiments for citrate, $^{[2 \mathrm{~d}, 2 \mathrm{~g}]}$ and later by single crystal X-ray diffraction for all three polycarboxylates. ${ }^{[4-6,9,10,12,15]}$ In the solid state, these dimers can be assembled into higher dimensionality coordination polymers by further carboxylate bridging, involving either two or four uranyl cations, or two uranyl and one or two d-block metal cations. However, although d-block metal cations are often used to increase the dimensionality in uranyl-organic species, ${ }^{[38]}$ this is not always the case here. A summary of the species described in this and previous work with these three ligands is given in Scheme 2. It is notable that the ubiquitous formation of 1D polymeric chains through uranyl bridging always involves the $-\mathrm{CH}_{2}-\mathrm{COO}^{-}$groups, which is probably due to the geometry of the five- and six-membered chelate rings in the dimer. The six-membered ring typically assumes a boat conformation with the carboxylate oxygen atom and one carbon atom displaced out of the 


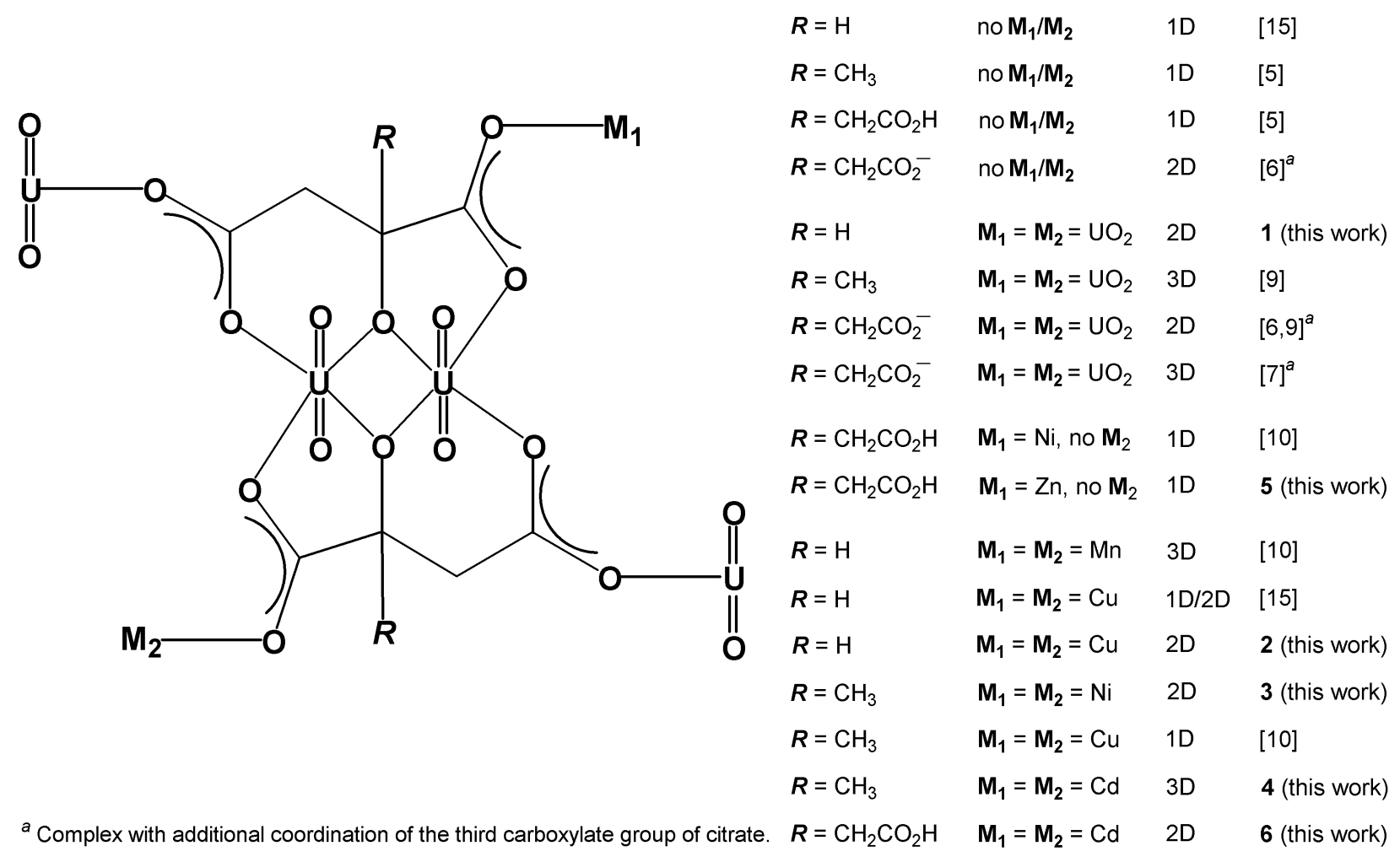

Scheme 2. The bonding mode and dimensionality in polymeric malate, citramalate and citrate homo- and heterometallic uranyl complexes based on the 2:2 dimeric motif.

plane defined by the four other atoms, and this induces a tilting of the carboxylate group out of the mean plane of the dimer; in contrast, the five-membered ring is nearly planar and the carboxylate group is coplanar with it, a geometry seemingly less favorable for the formation of the eight-membered inter-dimer ring. The two remaining carboxylate oxygen atoms not bound to uranyl ions may be either left uncoordinated, thus giving simple $1 \mathrm{D}$ chains, ${ }^{[5,15]}$ or bound to two more uranyl ions, thus giving a $2 \mathrm{D}$ network as in the malate complex $\mathbf{1}$ or a 3D framework with citramalate, ${ }^{[9]}$ or bound to either one or two d-block metal cations, which, depending on their terminal or bridging nature (associated with the presence of oxalate ligands in one case), 
are simple decorating species as in complex 5, or increase the dimensionality as in $\mathbf{2}, \mathbf{3}$ and $\mathbf{6}$ (their role in 4 being probably more that of a structure-directing agent since a 3D framework is formed through uranyl connectivity alone). In the present instances of complexes of $R, S$-malic, $R$ citramalic and citric acids, the hydroxyl group is bound in its deprotonated form and appears to form a strong bridge between pairs of uranium ions but deprotonation of the bound hydroxyl group is not seen in $\left[\left(\mathrm{UO}_{2}\right)_{3}(\mathrm{Hcit})_{2}\left(\mathrm{H}_{2} \mathrm{O}\right)_{3}\right] \cdot 2 \mathrm{H}_{2} \mathrm{O},{ }^{3}$ for example, and the oxygen does not bridge metal ions (the ligand there being a tautomeric form of the species seen in the present cases). The absence of the hydroxyl group makes tricarballylate a quite different ligand, with no close dimer formation. Complex 7, obtained with lead(II) cations alone, differs from $\left[\mathrm{NH}_{4}\right]\left[\left(\mathrm{UO}_{2}\right)_{2} \mathrm{~Pb}(\mathrm{tca})_{2}\left(\mathrm{NO}_{3}\right)\right.$ (bipy)], ${ }^{[17]}$ since $\mathrm{Pb}$ "l serves as a framework fourfold node in the former, while $\mathrm{Pb}\left(\mathrm{NO}_{3}\right)(\text { bipy })^{+}$moieties are simple links uniting uranyl-based nanotubules into a $2 \mathrm{D}$ network in the latter. A subtle feature of the coordination chemistry of citrate and tricarballylate, both of which are prochiral molecules, is the chirality which may be induced by unsymmetrical coordination, the consequences of which may include influencing the chirality of substituents attached to a coordination polymer chain and the crystalline form of the solid complex. The different dimensionalities and topologies achieved in uranyl complexes with malic, citramalic, citric and tricarballylic acids through the use of different connecting moieties based on additional metal cations, even in the cases when the same dimeric subunit is present, added to the possibility of induction of chirality by unsymmetrical coordination with the last two ligands, make this group of ligands one of remarkable versatility for uranyl ions. The uranyl emission spectra measured in the solid state for five of the complexes reported here give maxima positions in agreement with the trend previously found, those for the eight-coordinate complex being blue- 
shifted with respect to those for the seven-coordinate species, which, unsurprisingly given their essentially identical equatorial arrays involving three carboxylate-O and two alkoxo-O donor atoms, show very similar positions in their spectra, at least for the three most intensely emitting ones.

\section{Experimental Section}

General: $\mathrm{UO}_{2}\left(\mathrm{NO}_{3}\right)_{2} \cdot 6 \mathrm{H}_{2} \mathrm{O}$ (depleted uranium, R. P. Normapur, 99\%), $\mathrm{Pb}\left(\mathrm{NO}_{3}\right)_{2}$ and $\mathrm{Ni}\left(\mathrm{NO}_{3}\right)_{2} \cdot 6 \mathrm{H}_{2} \mathrm{O}$ were purchased from Prolabo, $\mathrm{Cu}\left(\mathrm{NO}_{3}\right)_{2} \cdot 2 \cdot 5 \mathrm{H}_{2} \mathrm{O}, \mathrm{Zn}\left(\mathrm{NO}_{3}\right)_{2} \cdot 6 \mathrm{H}_{2} \mathrm{O}$ and 1,10-phenanthroline (phen) were from Aldrich, $\mathrm{Cd}\left(\mathrm{NO}_{3}\right)_{2} \cdot 4 \mathrm{H}_{2} \mathrm{O}, R$-citramalic acid $\left(\mathrm{H}_{3} \mathrm{cml}\right)$, citric acid $\left(\mathrm{H}_{4} \mathrm{Cit}\right)$ and 2,2'-bipyridine (bipy) were obtained from Fluka, $R$,S-malic acid $\left(\mathrm{H}_{3} \mathrm{ml}\right)$ and 1,10-phenanthroline (phen) from Aldrich, and tricarballylic acid ( $\left.\mathrm{H}_{3} \mathrm{tca}\right)$ from Alfa Aesar. Elemental analyses for compounds 4, 6 and 7 were performed by MEDAC Ltd. at Chobham, UK. A similar analysis could not be conducted for the other compounds due to the low yield of the syntheses or the fact that a mixture of crystalline products was obtained.

Caution! Uranium is a radioactive and chemically toxic element, and uranium-containing samples must be handled with suitable care and protection.

[Ni(cyclam)( $\left.\mathrm{NO}_{3}\right)_{2}$ ]: Separate solutions of cyclam $(200 \mathrm{mg}, 1.00 \mathrm{mmol})$ in $\mathrm{CH}_{3} \mathrm{OH}(5 \mathrm{~mL})$ and $\mathrm{Ni}\left(\mathrm{NO}_{3}\right)_{2} \cdot 6 \mathrm{H}_{2} \mathrm{O}(290 \mathrm{mg}, 1.00 \mathrm{mmol})$ in $\mathrm{CH}_{3} \mathrm{OH}(5 \mathrm{~mL})$ were mixed to immediately provide a yellowbrown solution. A small amount of very insoluble yellow material was filtered out and the filtrate mixed with diethyl ether $(10 \mathrm{~mL})$ to cause precipitation of a pale violet solid. This was collected by filtration and washed with ether to give $\left[\mathrm{Ni}(\mathrm{cyclam})\left(\mathrm{NO}_{3}\right)_{2}\right]$ as a pale violet powder $(280 \mathrm{mg}$, $73 \%$ yield). 
$\left[\left(\mathrm{UO}_{2}\right)_{4}\left(\mathrm{ml}_{2}\left(\mathrm{C}_{2} \mathrm{O}_{4}\right)(\mathrm{NMP})_{4}\right](1): R\right.$, S-malic acid $(14 \mathrm{mg}, 0.10 \mathrm{mmol}), \mathrm{UO}_{2}\left(\mathrm{NO}_{3}\right)_{2} \cdot 6 \mathrm{H}_{2} \mathrm{O}(50 \mathrm{mg}, 0.10$ mmol), $\mathrm{N}$-methyl-2-pyrrolidone $(0.2 \mathrm{~mL})$, and demineralized water $(0.7 \mathrm{~mL})$ were placed in a 15 $\mathrm{mL}$ tightly closed glass vessel and heated at $140^{\circ} \mathrm{C}$ under autogenous pressure, giving light yellow crystals of complex 1 in low yield within three days. The yield was not improved upon prolonged heating.

[( $\left.\left.\mathrm{UO}_{2}\right)_{2} \mathrm{Cu}_{2}(\mathrm{ml})_{2}\left(\mathrm{C}_{2} \mathrm{O}_{4}\right)(\text { phen })_{2}\right]$ (2): $R$,S-malic acid $(14 \mathrm{mg}, 0.10 \mathrm{mmol}), \mathrm{UO}_{2}\left(\mathrm{NO}_{3}\right)_{2} \cdot 6 \mathrm{H}_{2} \mathrm{O}(50 \mathrm{mg}$, $0.10 \mathrm{mmol}), \mathrm{Cu}\left(\mathrm{NO}_{3}\right)_{2} \cdot 2.5 \mathrm{H}_{2} \mathrm{O}(24 \mathrm{mg}, 0.10 \mathrm{mmol}), 1,10$-phenanthroline (18 mg, $\left.0.10 \mathrm{mmol}\right), \mathrm{N}$ methyl-2-pyrrolidone $(0.2 \mathrm{~mL})$, and demineralized water $(0.7 \mathrm{~mL})$ were placed in a $15 \mathrm{~mL}$ tightly closed glass vessel and heated at $140{ }^{\circ} \mathrm{C}$ under autogenous pressure, giving dark green crystals of complex $\mathbf{2}$ in low yield within two weeks, mixed with crystals of complex $\mathbf{1 .}$

[( $\left.\left.\mathrm{UO}_{2}\right)_{2} \mathrm{Ni}(\mathrm{cml})_{2}(\mathrm{cyclam})\right]$ (3): $R$-citramalic acid $(15 \mathrm{mg}, 0.10 \mathrm{mmol}), \mathrm{UO}_{2}\left(\mathrm{NO}_{3}\right)_{2} \cdot 6 \mathrm{H}_{2} \mathrm{O}(50 \mathrm{mg}, 0.10$ $\mathrm{mmol}), \mathrm{Ni}(\mathrm{cyclam})\left(\mathrm{NO}_{3}\right)_{2}(20 \mathrm{mg}, 0.05 \mathrm{mmol})$, and demineralized water $(0.5 \mathrm{~mL})$ were placed in a $15 \mathrm{~mL}$ tightly closed glass vessel and heated at $140{ }^{\circ} \mathrm{C}$ under autogenous pressure, giving light yellow crystals of complex $\mathbf{3}$ in low yield within four days.

$\left[\left(\mathrm{UO}_{2}\right)_{2} \mathrm{Cd}(\mathrm{cml})_{2}(\right.$ bipy $\left.)\left(\mathrm{H}_{2} \mathrm{O}\right)_{2}\right]$ (4): $R$-citramalic acid $(15 \mathrm{mg}, 0.10 \mathrm{mmol}), \mathrm{UO}_{2}\left(\mathrm{NO}_{3}\right)_{2} \cdot 6 \mathrm{H}_{2} \mathrm{O}(50 \mathrm{mg}$, $0.10 \mathrm{mmol}), \mathrm{Cd}\left(\mathrm{NO}_{3}\right)_{2} \cdot 4 \mathrm{H}_{2} \mathrm{O}(16 \mathrm{mg}, 0.05 \mathrm{mmol}), 2,2^{\prime}$-bipyridine $(16 \mathrm{mg}, 0.10 \mathrm{mmol})$, acetonitrile $(0.2 \mathrm{~mL})$, and demineralized water $(0.7 \mathrm{~mL})$ were placed in a $15 \mathrm{~mL}$ tightly closed glass vessel and heated at $140{ }^{\circ} \mathrm{C}$ under autogenous pressure, giving light yellow crystals of complex 4 overnight (19 mg, 33\% yield). $\mathrm{C}_{20} \mathrm{H}_{22} \mathrm{CdN}_{2} \mathrm{O}_{16} \mathrm{U}_{2}$ (1134.85): calcd. C 21.17, $\mathrm{H} 1.95, \mathrm{~N} 2.47$; found $\mathrm{C} 21.06, \mathrm{H}$ 1.90, N 2.69.

[( $\left.\left(\mathrm{UO}_{2}\right)_{2} \mathrm{Zn}(\mathrm{Hcit})_{2}(\text { bipy })_{2}\left(\mathrm{H}_{2} \mathrm{O}\right)\right]$ (5): Citric acid $(20 \mathrm{mg}, 0.10 \mathrm{mmol}), \mathrm{UO}_{2}\left(\mathrm{NO}_{3}\right)_{2} \cdot 6 \mathrm{H}_{2} \mathrm{O}(50 \mathrm{mg}, 0.10$ mmol), $\mathrm{Zn}\left(\mathrm{NO}_{3}\right)_{2} \cdot 6 \mathrm{H}_{2} \mathrm{O}(15 \mathrm{mg}, 0.05 \mathrm{mmol}), 2,2^{\prime}$-bipyridine (16 mg, $\left.0.10 \mathrm{mmol}\right)$, acetonitrile $(0.2$ 
$\mathrm{mL})$, and demineralized water $(0.6 \mathrm{~mL})$ were placed in a $15 \mathrm{~mL}$ tightly closed glass vessel and heated at $140{ }^{\circ} \mathrm{C}$ under autogenous pressure, giving light yellow crystals of complex $\mathbf{5}$ in low yield within three days.

[(UO $\left.)_{2} \mathrm{Cd}(\mathrm{Hcit})_{2}(\text { bipy })_{2}\right]$ (6): Citric acid $(20 \mathrm{mg}, 0.10 \mathrm{mmol}), \mathrm{UO}_{2}\left(\mathrm{NO}_{3}\right)_{2} \cdot 6 \mathrm{H}_{2} \mathrm{O}(50 \mathrm{mg}, 0.10 \mathrm{mmol})$, $\mathrm{Cd}\left(\mathrm{NO}_{3}\right)_{2} \cdot 4 \mathrm{H}_{2} \mathrm{O}$ (16 mg, $\left.0.05 \mathrm{mmol}\right), 2,2^{\prime}$-bipyridine (16 mg, $\left.0.10 \mathrm{mmol}\right)$, acetonitrile $(0.2 \mathrm{~mL})$, and demineralized water $(0.6 \mathrm{~mL})$ were placed in a $15 \mathrm{~mL}$ tightly closed glass vessel and heated at 140 ${ }^{\circ} \mathrm{C}$ under autogenous pressure, giving light yellow crystals of complex 6 within three days (37 mg, $55 \%$ yield). $\mathrm{C}_{32} \mathrm{H}_{26} \mathrm{CdN}_{4} \mathrm{O}_{18} \mathrm{U}_{2}$ (1343.03): calcd. C 28.62, $\mathrm{H}$ 1.95, N 4.17; found C 28.26, H 2.23, N 4.32 .

$\left[\left(\mathrm{UO}_{2}\right)_{2} \mathrm{~Pb}(\mathrm{tca})_{2}\left(\mathrm{H}_{\mathbf{2}} \mathrm{O}\right)_{4}\right]$ (7): Tricarballylic acid $(18 \mathrm{mg}, 0.10 \mathrm{mmol}), \mathrm{UO}_{2}\left(\mathrm{NO}_{3}\right)_{2} \cdot 6 \mathrm{H}_{2} \mathrm{O}(50 \mathrm{mg}, 0.10$ $\mathrm{mmol}), \mathrm{Pb}\left(\mathrm{NO}_{3}\right)_{2}(33 \mathrm{mg}, 0.10 \mathrm{mmol})$, and demineralized water $(0.7 \mathrm{~mL})$ were placed in a $15 \mathrm{~mL}$ tightly closed glass vessel and heated at $140{ }^{\circ} \mathrm{C}$ under autogenous pressure, giving light yellow crystals of complex 7 within four days (11 mg, 19\% yield based on $U$ ). $\mathrm{C}_{12} \mathrm{H}_{18} \mathrm{O}_{20} \mathrm{PbU}_{2}$ (1165.51): calcd. C 12.37, H 1.56; found C 12.38, H 1.60.

Crystallography: The data were collected at 150(2) K on a Nonius Kappa-CCD area detector diffractometer $^{[39]}$ using graphite-monochromated Mo K $\alpha$ radiation $(\lambda=0.71073 \AA)$. The crystals were introduced into glass capillaries with a protective coating of Paratone-N oil (Hampton Research). The unit cell parameters were determined from ten frames, then refined on all data. The data (combinations of $\varphi$ - and $\omega$-scans with a minimum redundancy of at least 4 (10 for compound 4) for $90 \%$ of the reflections) were processed with HKL2000. ${ }^{[40]}$ Absorption effects were corrected for empirically with the program SCALEPACK. ${ }^{[40]}$ The structures were solved by 
intrinsic phasing with SHELXT ${ }^{[41]}$ or by Patterson map interpretation with SHELXS, ${ }^{[42]}$ expanded by subsequent difference Fourier synthesis and refined by full-matrix least-squares on $F^{2}$ with SHELXL-2014. ${ }^{[43]}$ All non-hydrogen atoms were refined with anisotropic displacement parameters. The hydrogen atoms bound to oxygen or nitrogen atoms were found on difference Fourier maps, and the carbon-bound hydrogen atoms were introduced at calculated positions; all hydrogen atoms were treated as riding atoms with an isotropic displacement parameter equal to 1.2 times that of the parent atom ( 1.5 for $\mathrm{CH}_{3}$, with optimized geometry). Crystal data and structure refinement parameters are given in Table 1. The molecular plots were drawn with ORTEP-3 ${ }^{[44]}$ and the polyhedral representations with VESTA. ${ }^{[45]}$ Special details are as follows:

Compound 1. Atoms $\mathrm{U} 1,01,02,07,08, \mathrm{C} 2$ and $\mathrm{C} 3$ are disordered over two positions which have been refined with occupancy parameters constrained to sum to unity. These two sets of positions correspond to the two enantiomorphs, $R$ and $S$, of the malate ligand.

Compound 5. Large voids in the lattice indicate the presence of badly resolved solvent molecules which could not be modelled properly. The corresponding electron density was masked with PLATON/SQUEEZE. ${ }^{[46]}$

Compound 6. Extensive disorder is present, which was not removed by resolving the structure in space groups of lower symmetry such as $\mathrm{C} 2$. The $\mathrm{Cd}(\text { bipy })_{2}$ group is disordered over two positions related by a twofold rotation axis, and it has been refined with half-occupancy accordingly. The carboxylate group containing $\mathrm{O5}$ and $\mathrm{O6}$ is rotationally disordered and the two oxygen components were refined with occupancy parameters constrained to sum to unity. Atom $\mathrm{O} 8$ is also disordered over two positions which were given occupancy parameters of 0.5 ; further disorder on the other atoms of this carboxylate group was not resolved. Two aromatic rings 
(containing N3 and N4) were refined as idealized hexagons. Restraints on displacement parameters were applied for atom O5B and the carbon atoms of the bipy molecules.

CCDC-1588119-1588125 contain the supplementary crystallographic data for this paper. These data can be obtained free of charge from The Cambridge Crystallographic Data Centre via www.ccdc.cam.ac.uk/data request/cif.

Table 1. Crystal data and structure refinement details.

\begin{tabular}{|c|c|c|c|c|c|c|c|}
\hline & 1 & 2 & 3 & 4 & 5 & 6 & 7 \\
\hline Empirical formula & $\mathrm{C}_{30} \mathrm{H}_{42} \mathrm{~N}_{4} \mathrm{O}_{26} \mathrm{U}_{4}$ & $\mathrm{C}_{34} \mathrm{H}_{22} \mathrm{Cu}_{2} \mathrm{~N}_{4} \mathrm{O}_{18} \mathrm{U}_{2}$ & $\mathrm{C}_{20} \mathrm{H}_{34} \mathrm{~N}_{4} \mathrm{NiO}_{14} \mathrm{U}_{2}$ & $\mathrm{C}_{20} \mathrm{H}_{22} \mathrm{CdN}_{2} \mathrm{O}_{16} \mathrm{U}_{2}$ & $\mathrm{C}_{32} \mathrm{H}_{28} \mathrm{~N}_{4} \mathrm{O}_{19} \mathrm{U}_{2} \mathrm{Zn}$ & $\mathrm{C}_{32} \mathrm{H}_{26} \mathrm{CdN}_{4} \mathrm{O}_{18} \mathrm{U}_{2}$ & $\mathrm{C}_{12} \mathrm{H}_{18} \mathrm{O}_{20} \mathrm{PbU}_{2}$ \\
\hline$M\left(\mathrm{~g} \mathrm{~mol}^{-1}\right)$ & 1826.80 & 1377.69 & 1089.28 & 1134.85 & 1314.01 & 1343.03 & 1165.51 \\
\hline Crystal system & triclinic & triclinic & triclinic & monoclinic & triclinic & monoclinic & orthorhombic \\
\hline Space group & $P_{\bar{I}}$ & $P_{\bar{I}}^{\bar{I}}$ & $P 1$ & $P 2_{1}$ & $P_{\overline{\mathbf{I}}}$ & $C 2 / c$ & Pnnm \\
\hline$a(\AA)$ & $8.3551(4)$ & $8.2593(6)$ & $8.3975(6)$ & $13.1656(7)$ & $11.8429(8)$ & $25.6915(16)$ & $13.8259(6)$ \\
\hline$b(\AA)$ & $9.0472(6)$ & $10.9645(5)$ & $8.6969(11)$ & $14.0861(6)$ & $12.9737(9)$ & $8.5089(3)$ & $8.2399(3)$ \\
\hline$c(\AA)$ & $16.0320(11)$ & $11.3782(9)$ & $11.0955(13)$ & $24.5211(10)$ & $15.9199(8)$ & $20.3550(14)$ & $9.9133(3)$ \\
\hline$\alpha\left(^{\circ}\right)$ & $103.686(3)$ & $101.149(5)$ & $82.230(5)$ & 90 & $87.270(4)$ & 90 & 90 \\
\hline$\beta\left(^{\circ}\right)$ & $102.414(4)$ & $100.092(4)$ & $71.591(6)$ & $90.063(3)$ & $79.224(4)$ & $119.035(3)$ & 90 \\
\hline$\gamma\left({ }^{\circ}\right)$ & $90.107(4)$ & $108.635(5)$ & $78.529(6)$ & 90 & $63.595(3)$ & 90 & 90 \\
\hline$V\left(\AA^{3}\right)$ & $1148.15(13)$ & $926.30(11)$ & $751.22(14)$ & $4547.5(4)$ & $2150.5(2)$ & $3890.5(4)$ & $1129.36(7)$ \\
\hline$z$ & 1 & 1 & 1 & 6 & 2 & 4 & 2 \\
\hline$\rho_{\text {calcd }}\left(\mathrm{g} \mathrm{cm}^{-3}\right)$ & 2.642 & 2.470 & 2.408 & 2.486 & 2.029 & 2.293 & 3.427 \\
\hline$\mu\left(\mathrm{Mo}^{\left.-\mathrm{K}_{\alpha}\right)}\left(\mathrm{mm}^{-1}\right)\right.$ & 14.153 & 9.935 & 11.442 & 11.424 & 8.142 & 8.927 & 21.835 \\
\hline$F(000)$ & 826 & 640 & 506 & 3096 & 1228 & 2488 & 1032 \\
\hline Reflections collected & 63205 & 48302 & 35650 & 179251 & 93607 & 66477 & 27608 \\
\hline Independent reflections & 5913 & 3507 & 5646 & 17241 & 8155 & 3698 & 1542 \\
\hline Observed reflections $[I>2 \sigma(I)]$ & 5403 & 3201 & 5176 & 15769 & 6409 & 3150 & 1475 \\
\hline$R_{\text {int }}$ & 0.047 & 0.047 & 0.034 & 0.044 & 0.064 & 0.053 & 0.016 \\
\hline Parameters refined & 355 & 271 & 373 & 1118 & 523 & 374 & 89 \\
\hline$R_{1}$ & 0.036 & 0.030 & 0.055 & 0.035 & 0.039 & 0.029 & 0.018 \\
\hline $\mathrm{w} R_{2}$ & 0.087 & 0.060 & 0.148 & 0.076 & 0.102 & 0.072 & 0.041 \\
\hline$S$ & 1.271 & 1.074 & 1.044 & 1.015 & 0.992 & 1.047 & 1.099 \\
\hline$\Delta \rho_{\min }\left(\mathrm{e} \AA^{-3}\right)$ & -1.66 & -1.68 & -1.81 & -0.89 & -2.29 & -1.33 & -1.30 \\
\hline$\Delta \rho_{\max }\left(\mathrm{e} \AA^{-3}\right)$ & 1.28 & 2.18 & 3.51 & 1.42 & 2.38 & 1.36 & 0.80 \\
\hline Flack parameter & & & $-0.010(17)$ & $-0.006(3)$ & & & \\
\hline
\end{tabular}

Luminescence measurements: Emission spectra for compounds 3-7 were recorded on solid samples using a Horiba-Jobin-Yvon Fluorolog spectrofluorometer. The powdered complex was pressed between two silica plates which were mounted such that the faces were oriented vertically and at $45^{\circ}$ to the incident excitation radiation. An excitation wavelength of $420 \mathrm{~nm}$ was 
used in all cases and the emissions monitored between 450 and $650 \mathrm{~nm}$. The very low yield of the synthesis of $\mathbf{1}$ and $\mathbf{2}$ prevented luminescence measurements on these compounds.

\section{References}

[1] See, for example: a) A. J. Francis, C. J. Dodge, J. B. Gillow, Nature 1992, 356, 140-142; b) F. Y. C. Huang, P. V. Brady, E. R. Lindgren, P. Guerra, Environ. Sci. Technol. 1998, 32, 379382; c) F. Y. C. Huang, M. J. Blaylock, Y. Kapulnik, B. D. Ensley, Environ. Sci. Technol. 1998, 32, 2004-2008; d) A. J. Francis, C. J. Dodge, Environ. Sci. Technol. 1998, 32, 3993-3998; e) J. J. Lenhart, S. E. Cabaniss, P. MacCarthy, B. D. Honeyman, Radiochim. Acta 2000, 88, 345353; f) B. A. Logue, R. W. Smith, J. C. Westall, Environ. Sci. Technol. 2004, 38, 3752-3759; g) M. Carrière, C. Thiebault, S. Milgram, L. Avoscan, O. Proux, B. Gouget, Chem. Res. Toxicol. 2006, 19, 1637-1642; h) L. Bonin, G. Cote, P. Moisy, Radiochim. Acta 2008, 96, 145-152; i) S. Berto, F. Crea, P. G. Daniele, A. Gianguzza, A. Pettignano, S. Sammartano, Coord. Chem. Rev. 2012, 256, 63-81; j) G. D. Lawrence, K. S. Patel, A. Nusbaum, Pure Appl. Chem. 2014, 86, 1105-1110.

[2] See, for example: a) I. Feldman, C. A. North, H. B. Hunter, J. Phys. Chem. 1960, 64, 12241230; b) K. S. Rajan, A. E. Martell, Inorg. Chem. 1965, 4, 462-469; c) G. Markovits, P. Klotz, L. Newman, Inorg. Chem. 1972, 11, 2405-2408; d) P. G. Allen, D. K. Shuh, J. J. Bucher, N. M. Edelstein, T. Reich, M. A. Denecke, H. Nitsche, Inorg. Chem. 1996, 35, 784-787; e) S. P. Pasilis, J. E. Pemberton, Inorg. Chem. 2003, 42, 6793-6800; f) E. Vasca, G. Palladino, C. Manfredi, C. Fontanella, C. Sadun, R. Caminiti, Eur. J. Inorg. Chem. 2004, 2739-2746; g) E. H. Bailey, J. F. W. Mosselmans, P. F. Schofield, Chem. Geol. 2005, 216, 1-16; h) S. Berto, F. 
Crea, P. G. Daniele, C. De Stefano, E. Prenesti, S. Sammartano, Radiochim. Acta 2012, 100, $13-28$.

[3] P. Thuéry, Chem. Commun. 2006, 853-855.

[4] P. Thuéry, CrystEngComm 2007, 9, 358-360.

[5] P. Thuéry, Inorg. Chem. 2007, 46, 2307-2315.

[6] P. Thuéry, CrystEngComm 2008, 10, 79-85.

[7] P. Thuéry, B. Masci, Cryst. Growth Des. 2010, 10, 716-725.

[8] J. Lhoste, N. Henry, P. Roussel, T. Loiseau, F. Abraham, Dalton Trans. 2011, 40, 2422-2424.

[9] P. Thuéry, Eur. J. Inorg. Chem. 2013, 4563-4573.

[10] P. Thuéry, CrystEngComm 2013, 15, 6533-6545.

[11] M. Basile, D. K. Unruh, E. Flores, A. Johns, T. Z. Forbes, Dalton Trans. 2015, 44, 2597-2605.

[12] M. Basile, D. K. Unruh, K. Gojdas, E. Flores, L. Streicher, T. Z. Forbes, Chem. Commun. 2015, $51,5306-5309$.

[13] a) M. B. Andrews, C. L. Cahill, Chem. Rev. 2013, 113, 1121-1136; b) T. Loiseau, I. Mihalcea, N. Henry, C. Volkringer, Coord. Chem. Rev. 2014, 266-267, 69-109; c) J. Su, J. S. Chen, Struct. Bond. 2015, 163, 265-296; d) P. Thuéry, J. Harrowfield, Dalton Trans. 2017, 46, $13660-13667$.

[14] A. E. Martell, R. D. Hancock, R. J. Motekaitis, Coord. Chem. Rev. 1994, 133, 39-65.

[15] E. Cole, E. Flores, M. Basile, A. Jayasinghe, J. de Groot, D. K. Unruh, T. Z. Forbes, Polyhedron 2016, 114, 378-384.

[16] D. K. Unruh, K. Gojdas, E. Flores, A. Libo, T. Z. Forbes, Inorg. Chem. 2013, 52, 10191-10198.

[17] P. Thuéry, J. Harrowfield, Cryst. Growth Des. 2017, 17, 963-966. 
[18] See, for example: a) P. Thuéry, Cryst. Growth Des. 2014, 14, 901-904; b) P. Thuéry, J. Harrowfield, Cryst. Growth Des. 2014, 14, 1314-1323; c) P. Thuéry, J. Harrowfield, CrystEngComm 2014, 16, 2996-3004; d) P. Thuéry, E. Rivière, J. Harrowfield, Inorg. Chem. 2015, 54, 2838-2850; e) P. Thuéry, J. Harrowfield, Inorg. Chem. 2017, 56, 1455-1469.

[19] P. Thuéry, J. Harrowfield, Inorg. Chem. 2015, 54, 8093-8102, and references therein.

[20] a) M. B. Andrews, C. L. Cahill, CrystEngComm 2011, 13, 7068-7078; b) K. E. Knope, H. Kimura, Y. Yasaka, M. Nakahara, M. B. Andrews, C. L. Cahill, Inorg. Chem. 2012, 51, 38833890.

[21] E. Munir, J. J. Yoon, T. Tokimatsu, T. Hattori, M. Shimada, PNAS 2001, 98, 11126-11130.

[22] C. R. Groom, I. J. Bruno, M. P. Lightfoot, S. C. Ward, Acta Crystallogr., Sect. B 2016, 72, 171-179.

[23] M. A. Spackman, D. Jayatilaka, CrystEngComm 2009, 11, 19-32, and references therein.

[24] S. K. Wolff, D. J. Grimwood, J. J. McKinnon, M. J. Turner, D. Jayatilaka, M. A. Spackman, CrystalExplorer, University of Western Australia, 2012.

[25] a) R. Taylor, O. Kennard, J. Am. Chem. Soc. 1982, 104, 5063-5070; b) G. R. Desiraju, Acc. Chem. Res. 1996, 29, 441-449.

[26] A. L. Spek, Acta Crystallogr., Sect. D 2009, 65, 148-155.

[27] a) B. Bosnich, R. Mason, P. J. Pauling, G. B. Robertson, M. L. Tobe, Chem. Commun. 1965, 97-98; b) B. Bosnich, M. L. Tobe, G. A. Webb, Inorg. Chem. 1965, 4, 1109-1112.

[28] a) B. Bosnich, C. K. Poon, M. L. Tobe, Inorg. Chem. 1965, 4, 1102-1108; b) E. K. Barefield, A. Bianchi, E. J. Billo, P. J. Connolly, P. Paoletti, J. S. Summers, D. G. Van Derveer, Inorg. Chem. 1986, 25, 4197-4202. 
[29] V. A. Blatov, TOPOS, Samara State University, Russia, 2004.

[30] a) H. Miyamae, K. Yoshinari, G. Hihara, M. Nagata, Acta Crystallogr., Sect. C 1988, 44, 1528-1530; b) E. Psillakis, J. C. Jeffery, J. A. McCleverty, M. D. Ward, Chem. Commun. 1997, 1965-1966.

[31] L. Shimoni-Livny, J. P. Glusker, C. W. Bock, Inorg. Chem. 1998, 37, 1853-1867.

[32] K. E. Knope, D. T. de Lill, C. E. Rowland, P. M. Cantos, A. de Bettencourt-Dias, C. L. Cahill, Inorg. Chem. 2012, 51, 201-206.

[33] A. Brachmann, G. Geipel, G. Bernhard, H. Nitsche, Radiochim. Acta 2002, 90, 147-153.

[34] A. T. Kerr, C. L. Cahill, Cryst. Growth Des. 2014, 14, 1914-1921.

[35] P. Thuéry, J. Harrowfield, Inorg. Chem. 2017, 56, 13464-13481.

[36] a) M. P. Redmond, S. M. Cornet, S. D. Woodall, D. Whittaker, D. Collison, M. Helliwell, L. S. Natrajan, Dalton Trans. 2011, 40, 3914-3926; b) L. S. Natrajan, Coord. Chem. Rev. 2012, $256,1583-1603$.

[37] a) P. Thuéry, J. Harrowfield, Cryst. Growth Des. 2014, 14, 1314-1323; b) R. G. Surbella, III, M. B. Andrews, C. L. Cahill, J. Solid State Chem. 2016, 236, 257-271; c) N. P. Martin, C. Falaise, C. Volkringer, N. Henry, P. Farger, C. Falk, E. Delahaye, P. Rabu, T. Loiseau, Inorg. Chem. 2016, 55, 8697-8705.

[38] K. X. Wang, J. S. Chen, Acc. Chem. Res. 2011, 44, 531-540.

[39] R. W. W. Hooft, COLLECT, Nonius BV: Delft, The Netherlands, 1998.

[40] Z. Otwinowski, W. Minor, Methods Enzymol. 1997, 276, 307-326.

[41] G. M. Sheldrick, Acta Crystallogr., Sect. A 2015, 71, 3-8.

[42] G. M. Sheldrick, Acta Crystallogr., Sect. A 2008, 64, 112-122. 
[43] G. M. Sheldrick, Acta Crystallogr., Sect. C 2015, 71, 3-8.

[44] L. J. Farrugia, J. Appl. Crystallogr. 1997, 30, p. 565.

[45] K. Momma, F. Izumi, J. Appl. Crystallogr. 2008, 41, 653-658.

[46] A. L. Spek, Acta Crystallogr., Sect. C 2015, 71, 9-18.

Table of Contents Entry

\section{Uranyl Ion Complexes with Chiral Malic and Citramalic, and Prochiral Citric and Tricarballylic Acids: Influence of Coligands and Additional Metal Cations}

Pierre Thuéry and Jack Harrowfield

Key Topic: Uranyl-Based Network Solids

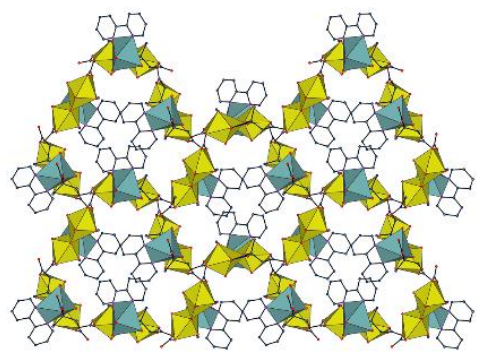

While all the $R, S$-malate, $R$-citramalate and citrate uranyl complexes described here contain the same dimeric subunit with bridging alkoxide donors, variations in the additional species present (d block metal cations and coligands) result in the formation of one-, two- or three-dimensional coordination polymers, a three-dimensional framework being also found in a uranyl-lead(II) tricarballylate complex. Uranyl emission maxima positions for complexes with five equatorial donors are red-shifted with respect to those for the complex with six donors. 